\title{
DESIGN ASPECTS OF THE ALPHA REPOSITORY: \\ VI. SELECTION AND COST ANALYSIS OF \\ LARGE HOLE DRILLING EQUIPMENT
}

Technical Memorandum Report RSI-0032

David B. Ellis

William H. Grams

June 30,1975

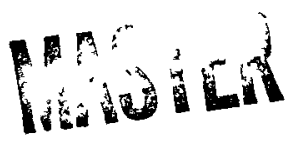

This report was prepared by RE/SPEC, Inc. under Subcontract 4269 with Union Carbide Corporation, Nuclear Division. The subcontract was administered by Oak Ridge National Laboratory

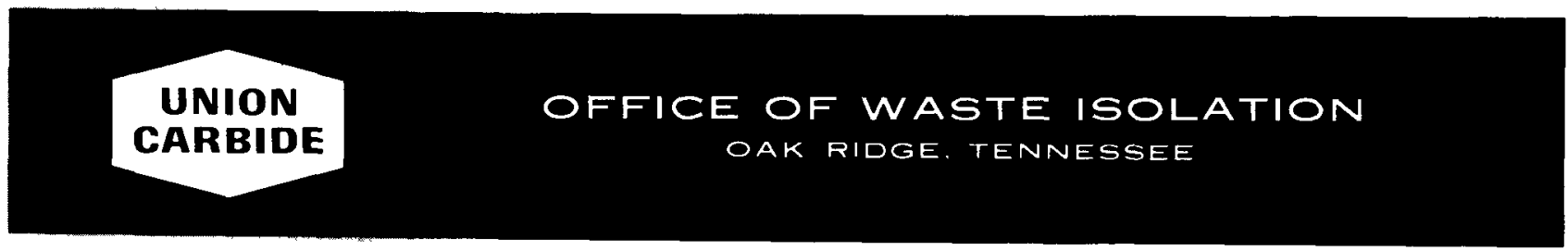

prepared for the U.S. ENERGY RESEARCH AND DEVELOPMENT ADMINISTRATION under U.S. GOVERNMENT Contract W-7405 eng 26

This informal document contains information which is preliminary and may be fragmentary or of limited scope. The assumptions, views, and conclusions expressed in this document are those of the authors and are not to be interpreted as those of Union Carbide Corporation, Nuclear Division, or USERDA 


\section{DISCLAIMER}

This report was prepared as an account of work sponsored by an agency of the United States Government. Neither the United States Government nor any agency Thereof, nor any of their employees, makes any warranty, express or implied, or assumes any legal liability or responsibility for the accuracy, completeness, or usefulness of any information, apparatus, product, or process disclosed, or represents that its use would not infringe privately owned rights. Reference herein to any specific commercial product, process, or service by trade name, trademark, manufacturer, or otherwise does not necessarily constitute or imply its endorsement, recommendation, or favoring by the United States Government or any agency thereof. The views and opinions of authors expressed herein do not necessarily state or reflect those of the United States Government or any agency thereof. 


\section{DISCLAIMER}

Portions of this document may be illegible in electronic image products. Images are produced from the best available original document. 


\section{Holifield National Laboratory}

oak Ridge, Tennessee

operated by

Union Carbide Corporation

Nuclear Division

for the

Energy Research and Development Administration

by

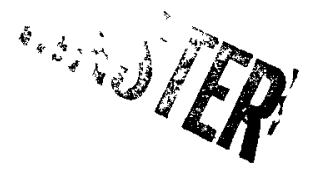

David B. Ellis

William H. Grams
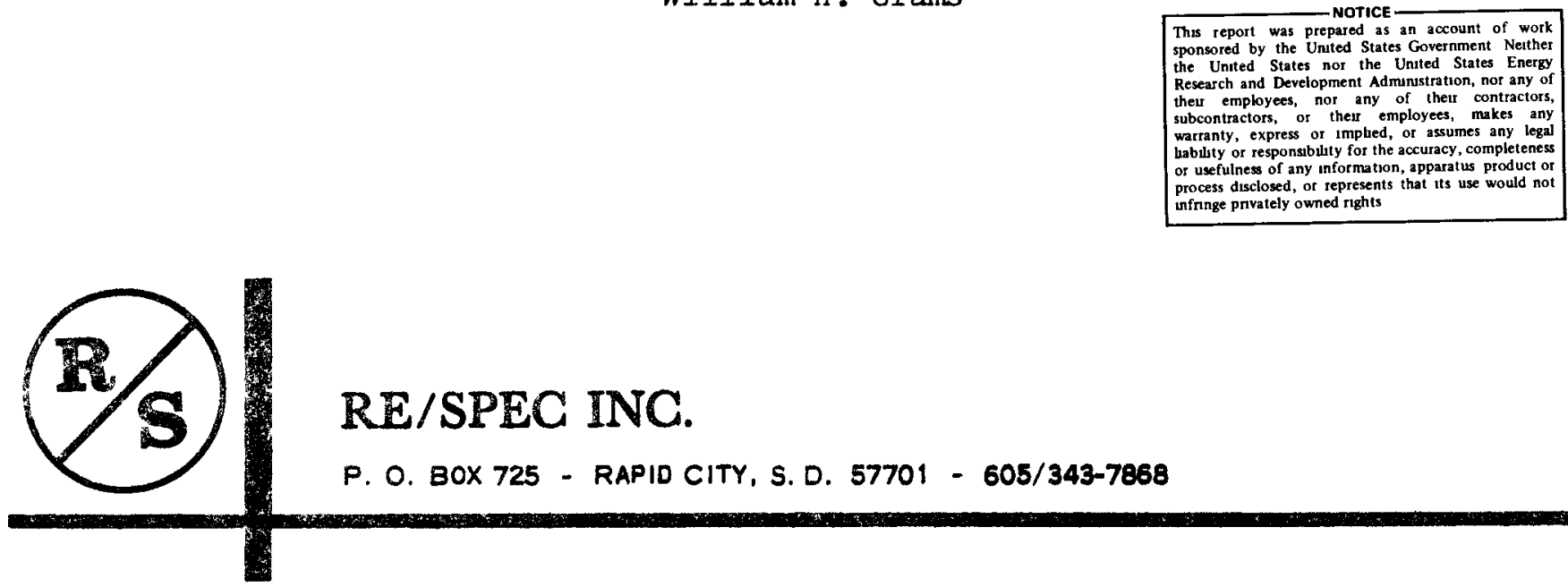

\section{RE/SPEC INC.}

P. O. BOX 725 - RAPID CITY, S. D. 57701 - 605/343-7868 
TECHNICAL MEMORANDUM REPORT RSI-0032

DESIGN ASPECTS OF THE ALPHA REPOSTTORY:

VI. SELECTION AND COST ANALYSIS OF LARGE HOLE DRILLING EQUIPMENT

\author{
Submitted To \\ Holifield National Laboratory \\ Oak Ridge, Tennessee \\ operated by \\ Union Carbide Corporation \\ Nuclear Division \\ for the \\ Energy Research and Development Administration
}

by

David B. Ellis

William H. Grams

of

$R E / S P E C$ InC.

Rapid City, South Dakota

June 30,1975 
1. SUMMARIZED DISCUSSION OF LARGE HOLE DRILLING IN ROCK SALT 1

1.1. Statement of Objectives 1

1.2. Summarized Discussion of Drilling Methods and 2 Equipment

1.3. Specific Equipment Proposals 4

1.4. Anticipated Drilling Costs 7

1.5. Conclusions and Recommendations 8

2. OPERATIONAL CONSIDERATIONS OF DRILLING SYSTEM APPLICATIONS 13

2.1. Characteristics of Drilling Methods 13

2.1.1. Core Drilling 13

2.1.2. Rotary Drilling 13

2.1.3. Percussion Drills 16

2.2. Characteristics of Drilling Machines 16

2.3. Characteristics of Drill Cuttings Removal Methods 18

2.4. Characteristics of Dust Control Methods 21

3. DESCRIPTION OF DRILIING AS OBTAINED THROUGH INQUIRY TO 23 MANUFACTURERS

3.1. General Remarks 23

3.2. Acker Drill Company; Scranton, $P A \quad 25$

3.3. Calweld, Division of Smith International, Inc.; 28 Santa Fe Springs, CA

3.4. Cyclone Drill Company; Orrville, $\mathrm{OH} \quad 29$

3.5. The Robbins Company; Seattle, WA 31

3.6. Schramm Inc.; West Chester, PA 34

3.7. Dresser Industries, Inc.; Dallas, $T X \quad 34$

3.8. Ingersoll-Rand Company; Seattle, WA 38

3.9. Atlas Copco, MCT AB; Sweden 40

4. DRTLL SYSTEM PERFORMANCE AND COST SIMULATION 41

4.1. Specifications and Assumptions for Large Hole Drill 41 Simulation

4.2. Description of Simulation Program 43

4.3. Simulation Results 43

4.4. Contractor's Estimate Compared to Simulation Results 45

REFERENCES 53

APPENDIX A: Drill Simulation Output Example A-1 
(RSI-0032)

\section{LIST OF FIGURES}

Figure

Page

1.1. Estimated Cost per Hole for Five Representative Drilling

Machines for the Lower Limit of 12 Inch Diameter Canisters, Two Canisters per 25 Foot Deep Hole.

2.1. Drag Bit

2.2. Tri-Cone Bit

2.3. Bucket Excavator Attached to Kelly Bar with Drag Type Bits

3.1. Truck Mounted, Top Head Drive Rotary Drill similar to Acker Drill Company, Model WA-I

3.2. Bucket Excavator, Rotary Drill with Extendable Kelly and Rotary Table; similar to Calweld, Division of Smith International, Inc. Model 150B

3.3. Crawler Mounted, Top Head Drive Rotary Drill with Roof Jacks and Drill Rod Handling Mechanism; similar to the Robbins Company Model $11 D$

3.4. Skid Mounted, Top Head Drive, Rotary Drill with Remote Electric/Hydraulic Power Pack; similar to Schraum, Inc. Mode1 $X 4016$

3.5. Small, Electrically Powered Core Drill; similar to Dresser Industries, Inc. BBS-15 Boyles Core Drill

3.6. Small, Crawler Mounted Percussive Drill; similar to 


\section{IIST OF TABLES}

Table

1.1. Cost Breakdown for the Upper and Lower Limits of Drilling

for the Bucket Excavator (Rotary) and Core Drills

1.2. Breakdown by percentage of personnel, material, and capital costs for five representative drilling machines for lower limit of 50,246 holes, 25 feet deep (corresponding to 12 inch diameter canisters, two canisters per hole).

4.1. Drill Simulation Input for Bucket Excavator, Rotary Drill 46

4.2. Drill Simulation Input for Core Drill 47

4.3. Drill Simulation Input for In-The-Hole Percussion Drill 48

4.4. Drill Simulation Input for Rotary Drill with Tricone 49 Bit and Hole Enlargex

4.5. Drill Simulation Input for Rotary Drill with Drag Bit 50 and Auger

4.6. Drill Simulation Results for Lower Limit of 12 inch diameter 51 canisters, two canisters per hole

4.7. Effects of Repository Size on Drill Simulation Results

\section{FOREWORD}

The technical content of this report has been reviewed by Dr. Paul F. Gnirk, Mr. Leo L. Van Sambeek, and Mr. Joe L. Ratigan of RE/SPEC InC. 
(RSI-0032)

R

S RE/SPEC ING.

P. O. BOX 725 RAPID CITY, S D $57701 \cdot 605 / 343.7868$

June 30,1975

TECHNICAL MEMORANDUM REPORT RSI-0032

TO: $\quad$ Dr. William C. MCClain

Holifield National Laboratory

P. O. BOX $Y$

Oak Ridge, TN 37830

FROM: Mr. David B. Ellis

Mr. William H. Grams

RE/SPEC InC.

P. O. BOX 725

Rapid City, SD 57701

SUBJECT: Design Aspects of the Alpha Repository: VI. Selection and Cost Analysis of Large Hole Drilling Equipment (Union Carbide Corporation, Nuclear Division Subcontract No. 4269; RSI/001000/ FY75) •

1. SUMMARIZED DISCUSSION OF LARGE HOLE DRILLING IN ROCK SALT

\subsection{Statement of objectives}

Large hole drilling is a specialized field normally associated with surface mining and construction. Drilling technology has most certainly progressed to the point where the task of drilling 30-inch diameter holes in rock salt would require no advances in the state-of-the-art. Nevertheless, there are a relative few drilling machines currently available which could perform the radioactive waste canister emplacement hole drilling task without major modifications. The overall objective of this report is to present an evaluation of common drilling practices and technology and applicability of currently available drilling machinery in the excavation of the canister emplacement holes for the Alpha Repasitory.

Manufacturers of both underground and surface drilling equipment were contacted and requested to supply information characteristic of their candidace machinery. Initially the drilling task was established as:

(1) 20 to 30 inch diameter holes in rock salt with stringers of anhydrite;

(2) Hole depths of 15 to 30 feet; 
(3) 4 feet between hole centers;

(4) 4 feet between rows of holes;

(5) 3 feet from rib of storage rooms to the center of the adjacent holes;

(6) Storage room minimum dimensions of 22 feet wide by 16 feet high;

(7) Minimum haulageway dimensions of 20 feet wide by 16 feet high. The scope of the investigation was later increased by including machinery capable of drilling smaller, 15 to 20 inch diameter, boreholes. The remaining portion of the hole drilling task (depth, spacing, etc.) remained unchanged.

To enable analysis and comparison of the drilling machinery, the manufacturers were requested to supply specifications such as type, size, power source, etc.; the effect of drilling through anhydrite stringers in rock; cutting removal system and dust control; and necessary modifications to the basic machines to enable performance of the canister emplacement hole drilling task.

Information was requested from a number of both domestic and foreign drilling equipment manufacturers. However, relatively few manufacturers presented machinery which could be used for drilling the canister emplacement holes. The data supplied by those manufacturers with suitable drilling equipment was used in a drilling production/cost simulation computer code, which provided an estimate of the overall drilling rate and expected costs for the specific drilling machines.

1.2. Sumarized Discussion of Drilling Methods and Equipment

\section{Drilling Techniques}

Three major drilling techniques were found to be applicable when drilling large diameter holes in rock salt; specifically:

(1) Core drizling;

(2) Rotary drilizing;

(3) Percussion drilling.

of the three techniques, only the core drilling equipment was found to be adaptable to the emplacement hole drilling task without major modifications. Both the percussion and rotary drilling equipment presented for analysis would require major modifications to enable drilling large diameter holes in rock salt.

\section{Drill Bits}

Four general classes of drill bits would be suitable for drilling rock sait with minor stringers of anhydrite: 
(1) Coring;

(2) Roller/Tricone;

(3) Drag;

(4) Percussion.

The coring bit, used in conjunction with the coring drills is a cylindrical tube with abrasive cutting inserts embedded in one end. Hormal coring bits use industrial grade diamonds as the abrasive; however, rock salt and anhydrite would not require an abrasive as hard as diamond for cutting the rock. Tungsten carbide inserts would be a good substitute.

koller/tricone bits are currently available for standard hole sizes up to $17 \frac{1}{2}$ inches in diameter; however, the large diameter holes would either require custom design bits, or the use of hole enlarging bits which utilize the large roller bits found on tunnel and raise boring equipment.

Drag bits are used in soft formations and would be well suited for drilling rock salt even if the stringers of anhydrite are present. For this application the drag bits should have replaceable, tungsten-carbide type cutter teeth. Percussion bits, used in conjunction with the in-the-hole percussion drills, would have to be custom made for this application. There are no standard bits currently available in the size range of this investigation. Cuttings Removal systems

Normally, cuttings removal from boreholes in underground mining situations poses no serious problems. The rock salt in this investigation does present an unusual problem since hole cleaning in underground mining is normally accomplished by water flushing, which would not work well in rock salt, even if a saturated salt brine is used. The water would tend to erode the borehole in addition to corroding metal parts of the drilling equipment, necessitating special designs employing corrosion resistant alloys. For this reason, three other methods of cuttings removal should be considered:

(I) Compressed air flushing;

(2) Augering;

(3) Bucket excavation.

Compressed air as a method of removing cuttings is the only possible mechanism which the in-the-hole percussion drilling technique uses due to the nature of the drilling machinery. It is also the most common mechanism utfized with rotary blast-hole drilling equipment. Two major problems could be anticlpated when compressed air is used as the flushing media. The first problem is associated with the size of the drill rod, where abnomally large ciameters 
are necessary for minimizing the annular area between the drill steel and the gauge diameter of the borehole to assure the correct air velocities for carrying the drill cuttings to the surface. These large diameter drill rods are not standard and would be custom designed for the corresponding drilling machine. The second problem involves the dust which is entrained in the air stream. Special equipment is available for dust control; however, its addition would possibly involve modification of the drilling machinery.

Augering is a method of cuttings removal which would not only eliminate dust, but conveniently remove the cuttings from the drillhole. The cuttings then could be easily transferred to auxiliary haulage equipment for removal from the storage rooms.

Bucket excavation is a common technique for removal of the drill cuttings from large diameter boreholes. While the bucket excavator is rotated, the rock is fractured by drag type cutters, integral to the bucket itself. The rotary motion of the bucket excavator fills the bucket, which is withdrawn from the borehole when full and emptied into auxiliary transport equipment. This system creates a minimum of dust and would require no specially designed equipment for conveying the drill cuttings away from the borehole.

\subsection{Specific Equipment Proposals}

Eight manufacturers presented equipment which they believed would be capable of performing the Alpha repository emplacement hole drilling task.

Acker Drill Company suggested a modified version of their model WA-I rotary drill using a drag bit and auger cutting removal. This machine requires extensive modification to enable it to perform the specified drilling tasks. In addition, the size of the machine would not enable drilling of the required number of emplacement holes in a room. No mechanism was provided for handling the sections of drill rod which would affect performance and safety.

Calweld, Division of Smith International, Inc. proposed using a modified version of their model $150 \mathrm{~B}$ bucket excavator drill. This machine is designed for drilling large holes in a variety of materials. Machines of this type are normally used to drill materials much weaker than rock salt, although the manufacturer claims to have effectively arilled fairly competent limestone and sandstone. The size of this drill would require modification to the tower to enable drilling in rooms with a height of 16 feet. The alignment of holes drilled with this type of machinery is questionable, probably limiting the hole depth to 15 or 20 feet. 
Cyclone Drill Company suggested using a modified version of their model TH-100 rotary drill with compressed air cuttings removal. This machine would require extensive modification to the extent that the drill would be considered a prototype machine. As presented, it would also pose maneuvering difficulties in the storage rooms and the haulageways due to the size of the machine.

The Robbins Company suggested using a modified track mounted version of their model $11 D$ rotary drill. Modifications of the drill would include increasing the diameter of the drill rod. This machine would probably work well, but it would require further design and modification to enable the cuttings to be transferred from the borehole to an auxiliary haulage system for removal from the storage rooms.

Schramm Inc. proposed using a specialty rotary drill, modei $x 4016$, developed for drilling elevator cylinder emplacement holes. The information received was not detailed enough for a total analysis of its drilling capabilities in rock salt. However, from the information received, the machine appears to require extensive redesign and modification to be able to perform the emplacement hole drilling task.

Dresser Industries proposed using a model BBS-15, Boyles core drill with a special tungsten carbide coring bit. A reverse circulation, vacuum cuttings removal dust control system was proposed, but no specific information was given. Core drilling is capable of excavating the canister emplacement holes; however production could be low if handling of the large, heavy sections of salt core poses a problem. In addition, cuttings removal using compressed air would cause a dust control problem requiring auxiliary dust removal equipment.

Ingersoll-Rand Company suggested using a model CMM/DHD in-the-hole percussion blast hole drill for the smaller range, 15-to 20-inch diameter emplacement holes. Modifications would be necessary to both the drill and the drilling bit before it could be capable of excavating the canister emplacement holes. Dust control would be a problem, possibly requiring special equipment beyond Ingersol1-Rand's standard water-injection dust control system.

Atlas-Copco, MCT $A B$, also proposed a machine very similar to the IngersollRand in design and capability. The drilling machine itself would have no definite advantage; however, Atlas-Copco markets a slightly larger percussion in-the-hole drill, which could possibly increase penetration rate.

Due to the lack of experience in drilling large holes in rock salt, the manufacturers of drilling equipment could only supply estimates of the drilling rates. In addition to excavating the borehole, the rate of hole 
production is dependent upon other factors including:

(1) Set up time;

(2) Drill steel addition-subtraction rate;

(3) Cuttings transfer time;

(4) Take down time;

These four factors and others are dependent upon the characteristics of the individual drilling machines and the operators. No drill, other than the core drilling equipment, is capable of performing the drilling tasks without major modifications; thus, the stochastic relationships necessary for modeling the drilling rates for the modified machines were not available. Nevertheless, most manufacturers who were contacted, predicted that a 20-inch diameter hole, 25 feet deep could be excavated in about one hour. of course, this time estimate neglects set up time, drill movement time, and other time consuming operations. None of the drilling equipment manufacturers believed that the presence of minor beds of anhydrite stringers in the stratigraphic section of the site rock would pose any serious problems. However, the overall drilling rate would decrease somewhat when the anhydrite stringers were encountered.

Additional ventilation in the storage rooms, over and above that required for the drillers and other workers, would not be required for any of the drilling machinery. The number of workers would vary with the type of drill used; generally, the minimum would be three: a driller, a driller's helper, and a shuttle car or load-haul-dump operator. Assuming the dust can be controlled, the minimum ventilation required would be 600 CFM per drill crew of three. Diesel-power drills would require considerably more ventilation, about 100 CFM per rated horsepower, depending upon the brand of diesel equipment used. Diesel power was not considered as the prime mover because control of the air quality in the vicinity of stationary diesel-powered equipment is complicated, and unnecessary when electrical and/or pneumatic power sources are readily available.

Power requirements for the drills that were presented ranged from approximately 15 horsepower for the small core drill to 150 horsepower for the larger rotary drills. The power requirement is primarily for rotation of the drill steel and application of the down force. If an air flushing system is used for removal of the drill cuttings, the power requirements would increase by approximately 200 horsepower, depending upon the quantity and pressure of the compressed air required and the efficiency of the system. All other functions, such as steel handling, tramming, etc. require relatively small amounts of power. 


\subsection{Anticipated Drilling Costs}

To establish a cost estimate for drilling the canister emplacement holes, a cost simulation was prepared for the following five specific drilling machines:

(1) Calweld, Division of Smith International, Inc.; Model 150B bucket excavator, rotary drill;

(2) Cyclone Drill Company; Model TH-100 rotary drill using tricone bits and compressed air flushing;

(3) Acker Drill Company; Nodel WA-l rotary drill using drag bits and auger cuttings removal;

(4) Dresser Industries, InC.; Model BBS-15 Boyles core drill;

(5) Ingersoll-Rand Company; Model CMM/DHD percussion in-the-hole drill. Two limiting cases for the number of holes necessary to store the anticipated number of waste canisters were considered. The lower limit is 50,114 holes, 20 inches in diameter excavated to a depth of 25 feet, corresponding to storing two canisters 12 inches in diameter, ten feet long in each hole. The upper limit is 144,305 holes, 20 inches in diameter, 15 feet deep, corresponding to storing one canister 10 inches in diameter, ten feet long in each hole. The Ingersoli-Rand Company percussion drill was not capable of efficiently drilling 20 inch diameter holes; therefore, the simulation for this machine was based upon 15 inch diameter holes.

For the lower limit, the cost per hole for the five representative driliing machines ranges from $\$ 85.41$ for the small percussion drill to $\$ 239.10$ for the core drilling machine, as illustrated in Figure 1.1. These costs do not include transportation of the cuttings from the repository. Total costs for drilling the lower limit of holes ranged from about 4.3 to 12.0 million dollars. A comparison of the three rotary drills, which had somewhat better cost input data, shows a cost per hole ranging from $\$ 133.38$ to $\$ 163.90$ with corresponding total costs of about 6.7 and 8.2 million.dollars, respectively.

The upper and lower limits on the number of required holes shows only a small effect on the drilling costs per hole. In comparing the upper and lower limit drilling costs, two representative drilling machines were used: the Calweld model $150 B$ bucket excavator rotary drill, and the Dresser BBS-15 Boyles core drill. Table 1.1 illustrates the upper and lower cost per hole for these two drills. As indicated in the table, only a slight increase is present in the cost per hole for the upper limit as compared to the lower limit for either drill. However, the cost per foot of hole drilled (the upper and lower limits requiring 15 and 25 foot hole depths, respectively) varies considerably between the upper and lower limit. The cost per foot for the 
lower limft is approximately 60 percent of that for the upper limit, and is a direct result of less freguent set-ups for the drilling machine. The total cost of drilling the upper limit of emplacement holes is about 32 mfllion dollars for the core drill and 23 million dollars for the bucket excavator rotary drill. For either drill, the upper limit drilling costs are about 2.7 times more than the lower limit.

\subsection{Conclusions and Recommendations}

Drilling the canister emplacement holes for the Alpha repository can be accomplished by a variety of common drilling techniques. However, standard equipment suitable for underground usage under the conditions anticipated in the proposed Alpha repository is very limited. Neglecting the small percussive drill which has the capability of drilling only smaller holes, the cost for drilling the emplacement holes could range from 7 to 12 million dollars for the lower limit of 50,114 holes, 25 feet deep, and from 22 to 32 million dollars for the upper limit of 144,305 holes, 15 feet deep. Table 1.2 displays the personnel, material, and capital expenditures as a percentage of the total cost for the five representative drilling machines when considering the lower limit of the number of holes necessary to complete the repository. Obviously, the cost of purchasing the operating equipment is the least amount of total expense.

None of the representative machines are ideally suited for the Alpha repository drilling task, and it is doubtful that a machine with the required capabilities would be available as standard equipment. To build a machine, with the required capabilities, a total investment of about $\$ 300,000.00$ would be necessary for design, detailing, fabrication, and testing. Such a drill would be not only extremely productive, but would also minimize overall costs by reducing labor and material costs. The ideal specifications which this machine should possess include:

(1) Electric/hydraulic power systems;

(2) Top head rotary drive;

(3) Auger cuttings removal with drag bits;

(4) Transfer conveyors to the auxiliary cuttings removal system;

(5) Integral dust control systems;

(6) Crawler mounted chassis;

(7) One man operation from a protected cab;

(8) Floor jack - roof jack stabilization;

(9) Major components common to standard production drills for spare parts availability. 
The construction of such a machine would require a major manufacturer of drilling equipment to design and fabricate the machine "in house", or closely coordinate the design/fabrication/testing effort with a specialty firm whose capabilities include engineering and manufacturing of the equipment. Costs could be kept relatively low by using as many standard proven components as possible, thus eliminating a major portion of the engineering design and providing good reliability usually not found in prototype machines. 


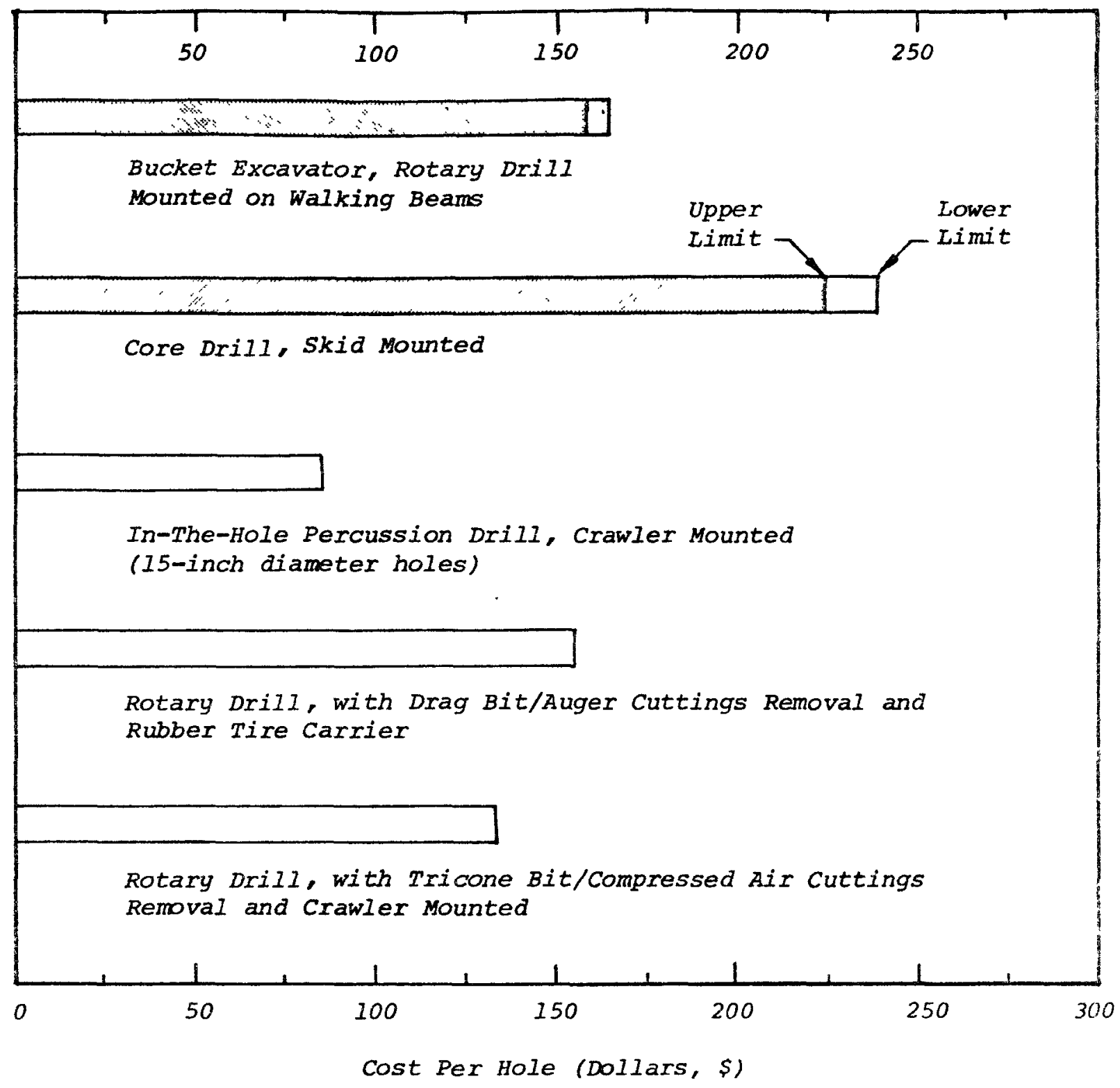

Figure 1.1. Estimated Cost per Hole for Five Representative Driliing Machines for the Lower Limit of 12 Inch Diameter Canisters, Two Canisters per 25 Foot Deep Hole.

NOTE: Costs per hole for the Upper limit of 10 inch diameter canisters, one canister per 15 foot deep hole were computed for the Hucket Excavator and the core Drill. 


\section{TABLE 1.1}

Cost Breakdown for the Upper and Lower Limits of prilling

for the Bucket Excavator (Rotary) and Core Drills

\begin{tabular}{|l|l|c|c|c|}
\hline Drilling Machine & \multicolumn{1}{|c|}{$\begin{array}{c}\text { Drilling } \\
\text { Requirements }\end{array}$} & $\begin{array}{c}\text { Cost } \\
\text { Per Hole }\end{array}$ & $\begin{array}{c}\text { Cost } \\
\text { Per Foot }\end{array}$ & $\begin{array}{c}\text { Total } \\
\text { Cost }\end{array}$ \\
\hline $\begin{array}{l}\text { Bucket Excavator, } \\
\text { Rotary Drill } \\
\text { Mounted on } \\
\text { Walking Beams } \\
\text { Lower Limit for } \\
\text { Emplacement of 12 inch } \\
\text { diameter canisters- } \\
\text { two canisters per hole }\end{array}$ & $\begin{array}{l}\text { I44,305 holes; } \\
\text { Upper Limit for } \\
\text { Emplacement of 10 inch } \\
\text { diameter canisters- } \\
\text { one canister per hole }\end{array}$ & 153.90 & $\$ 6.56$ & $\$ 8,235,213.00$ \\
\hline Core Drill, \\
Skid Mounted
\end{tabular}


Breakdown by percentage of personnel, material, and capital costs for five representative arilling machines for lower limit of 50,246 holes, 25 feet deep (corresponding to 12 inch diameter canisters, two canisters per hole).

\begin{tabular}{|l|c|c|c|}
\hline Drill & $\begin{array}{c}\text { Personnel } \\
\text { Cost } \%\end{array}$ & $\begin{array}{c}\text { Material } \\
\text { Cost } \%\end{array}$ & $\begin{array}{c}\text { Capital } \\
\text { Cost } \%\end{array}$ \\
\hline $\begin{array}{l}\text { Bucket Excavator, } \\
\text { Rotary Drill Mounted } \\
\text { on Walking Beams }\end{array}$ & $44 \%$ & $50 \%$ & $6 \%$ \\
\hline $\begin{array}{l}\text { Core Drill, } \\
\text { Skid Mounted }\end{array}$ & $25 \%$ & $74 \%$ & $1 \%$ \\
\hline $\begin{array}{l}\text { In-the-hole } \\
\text { Percussion Drill, } \\
\text { Crawler Mounted }\end{array}$ & $77 \%$ & $15 \%$ & $8 \%$ \\
\hline $\begin{array}{l}\text { Rotary Drill } \\
\text { with Drag Bit and } \\
\text { Continuous Auger, } \\
\text { Rubber Tire Carrier }\end{array}$ & $39 \%$ & $46 \%$ & $17 \%$ \\
\hline $\begin{array}{l}\text { Rotary Drill } \\
\text { with Hole Enlarger, } \\
\text { Crawler Mounted }\end{array}$ & $66 \%$ & $17 \%$ & $17 \%$ \\
\hline
\end{tabular}




\section{OPERATIONAL CONSIDERATIONS OF DRILLING SYSTEM APPLICATIONS}

\subsection{Characteristics of Drilling Methods}

\subsubsection{Core Drilling}

Core drilling is normally used in mineral exploration when information concerning the geology-at-depth is required. The core is cut away from the solid rock mass by a cylindrical hollow-tube bit attached to a hollow drill rod. The core bit is usually set with diamond inserts as a cutting media, although very soft rock can sometimes be economically cut with special tungsten carbide inserts.

The drill steel rotation and feed pressure for large drills employed in excavating a 20-inch diameter hole would be hydraulically controlled with pressure being supplied by electrically driven pumps. The cutting removal medium, which would also cool the drill bit, would be compressed air. The air flows down the hollow drill rod, through the annular area cut out by the drill bit, simultaneously entraining the cuttings and carrying them to the surface.

The large salt core would probably not split off from the parent rock by itself. Therefore, the bit would have to be withdrawn from the hole, and a wedge inserted in the annular space between the walls of the core and the parent rock in order to split the core away from the bottom of the hole before the core could be removed. The width of the annular space cut by a high production drill bit would probably be of the order of one inch or less.

For illustrative purposes, the cuttings from a 20-inch outside diameter hole with a 18-inch diameter core would weigh about 56 pounds per foot of hole drilled; or 1,700 pounds of cuttings for a hole depth of 30 feet. The core itself would weigh 240 pounds per foot, and would be removed in lengths of 3 to 5 feet; a 5 foot long core would weigh over 1,000 pounds.

A variety of problems arise when considering core drilling for excavation of the canister emplacement holes; viz;

(1) Low drilling rates,

(2) Finely powdered, possibly airborne cuttings,

(3) Hard-to-handle core sections.

These disadvantages may outweigh the advantages of low capital cost and low maintenance costs.

\subsubsection{Rotary Drilling}

Rotary drilling is the most versatile of all drilling methods. Materials 
ranging from overburden to taconite can be economically drilled by rotary methods. A drillhole is produced by forcing a rotating drill bit into the rock, which is broken by the pressure of the teeth as they drive into the rock mass. In general, the penetration rate for a given bit size is directly proportional to the force on the bit and inversely proportional to the strength of the rock. Penetration would thus increase as the force on the b1t is increased, at the expense of greater rotational torque requirements necessary for rotating the bit.

Two designs may be employed for the bit of the rotary drills: a drag type bit and a roller cone or tricone type bit, as illustrated in Figures 2.1 and 2.2, respectively. The drag bit has no moving parts. The rock is fractured by raking the teeth across the rock, thus shearing it away. The cones of the roller cone or tricone bit roll as the bit is rotated, forcing the teeth into the rock, and consequently crushing or fracturing it. In addition to the crushed rock directly beneath the teeth, larger chips are broken off along the periphery of the hole. The drag bit is used mainly in soft formations and would perform well in rock salt. The tricone bits are capable of efficiently drilling any type of rock by adjusting the shape and material of the teeth. Tricone bit-tooth profiles range from narrow wedges for drilling soft, plastic rocks to tungsten carbide buttons for drilling hard, brittle rocks.

The largest rotary blast hole drills for production drilling in open pit and strip mines are designed to drill 9-7/8 to 17-inch diameter blast holes. These drills weigh in the neighborhood of 100 tons, apply loads on the bit of around 130,000 pounds, and are set up to drill formations at high penetration rates. The large 20 to 30-inch diameter canister emplacement holes could be drilled with smaller machines at a considerable sacrifice in penetration rate. Force on the bit for surface drill rigs is limited by the weight of the machines. However, the drill for the canister emplacement holes could have almost unlimited down force as the drilling force could be increased by bracing the machine against the roof of the storage room.

A large hole drilling technique developed for low to high strength rock utilizes a hole expanding technique, employing equipment which is currently available off-shelf. A 9-7/8 inch diameter pilot hole is drilled with a standard tricone bit, followed by a hole expanding bit. The expander bit fractures the rock with the same high capacity roller cutters that are used on large raise borer back reamers. Excellent results with this drilling technique could be expected in rock salt. 


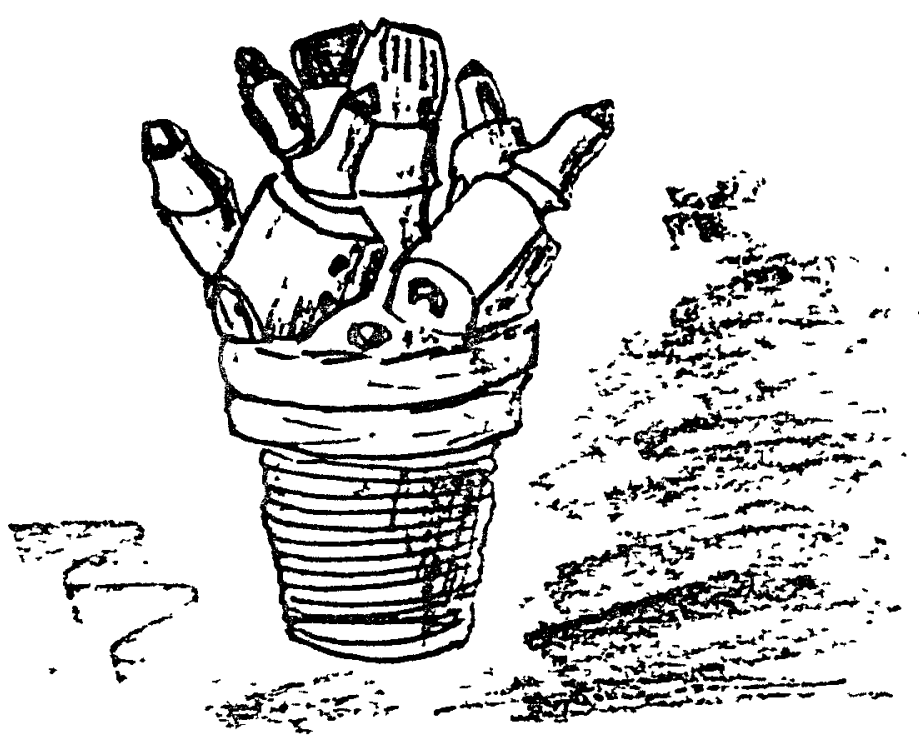

Figure 2.1. Drag Bit

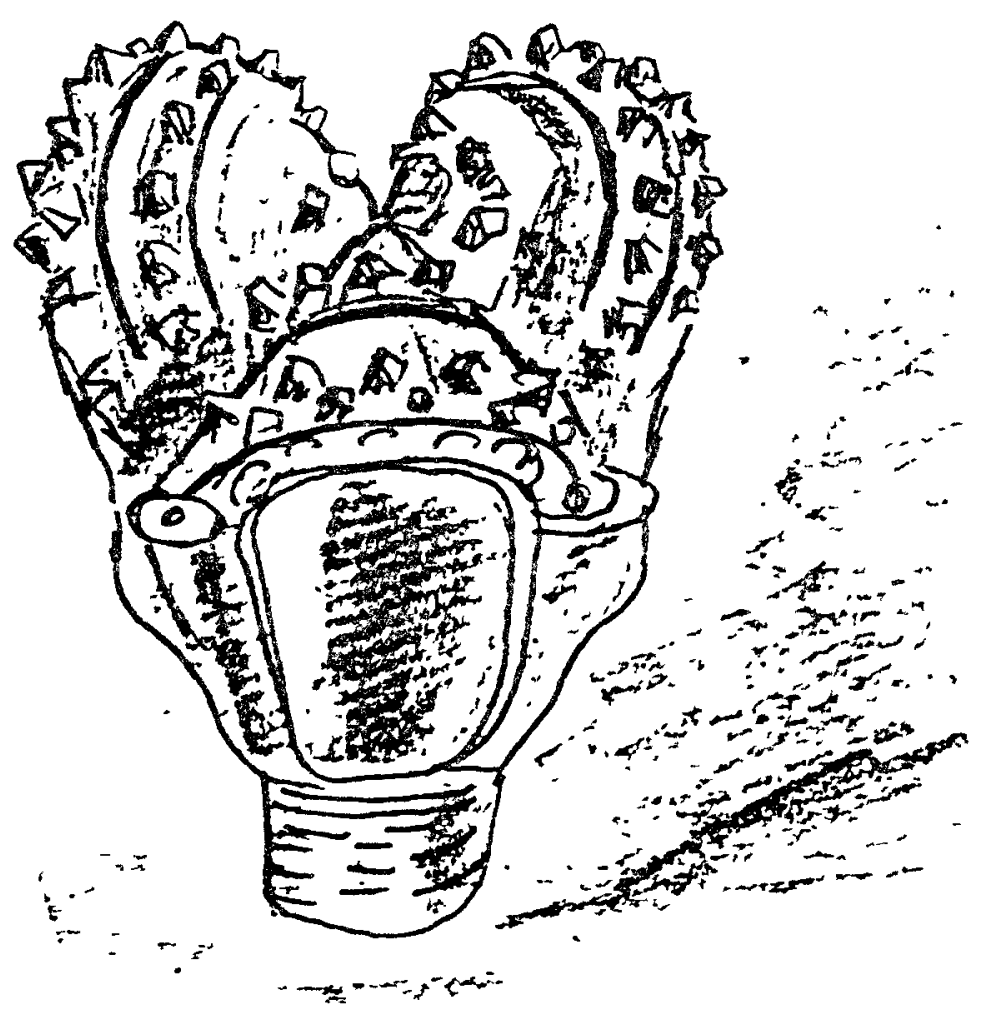

Figure 2.2. Tri-Cone Bit 


\subsubsection{Percussion Drills}

Percussion drills are the oldest form of rock drilling equipment. Hand held drill steel and sledge hammers were used as the primary drilling method until the 20th century, at which time steam and compressed air automated the system. In percussion drilling, the rock is broken by the resultant bit force caused by striking the drill steel with a hammer. Modern percussion drills use high-pressure compressed air of up to $250 \mathrm{psi}$ to activate the hamer mechanism.

In order to maximize drilling efficiency, an in-the-hole drill has been developed which places the hammer mechanism inside the drill hole. The compressed air is supplied to this hammer mechanism through the hollow drill steel and the hammer of the drill strikes directly against the bit, which eliminates the inefficiencies of force dissipation in the drill steel. The in-the-hole drill is the only efficient method of drilling large-diameter holes with percussion arills.

Most in-the-hole drills are designed to drill 4 to 6-inch diameter holes. special bits, used in conjunction with larger diameter drill rods, have been employed to drill holes in medium hard rock up to 18-inches in diameter. However, when the hole size is increased, the performance is severely compromised. Ingersol1-Rand Company has developed a very large in-the-hole drill, the DHD 124, capable of excavating a 24-inch diameter hole. This drill is 24 inches in diameter, $7 \frac{1}{2}$ feet long, and weighs over 3 tons. The DHD 124 would most certainly be very efficient in rock salt; however, a custom designed chassis would be necessary for this application, as the drill is presently used only in special surface drilling applications.

\subsection{Characteristics of Drilling Machines}

The makeup of any drilling machine involves five main sub-assemblies; viz:

(1) Main frame,

(2) Tower or mast,

(3) Rotary head or rotary table,

(4) Power pack,

(5) Operator controls.

The main frame is the base upon which all other components are mounted, if the drili rig is to be completely self contained. The propulsion or tramming ability is usually accomplished by heavy crawler assemblies, al though the smaller arills may be mounted on rubber tires.

The tower is the guide for the rotary head and drill feed assembly, and 
is constructed to resist the torque of the rotary head with minimum deflections. As most drill towers are fairly tall, stability when moving between holes is sometimes a problem. Crawler rigs are very wide, thus stable enough to tram with the tower in the up position; conversely, rubber-tired mounted drills normally require that the tower be lowered when moving between holes. The short tower height requirement for the drill to be used in the Alpha repository would present no problem, as regards stability, when tramning with either rubber tired or crawler tram assemblies.

Most large drill rigs contain a power pack, mounted on the main frame, which drives the main hydraulic system, crawler drives, air compressor, water pumps, and other accessory equipment. These power packs are normally diesel powered for the small to intermediate size drill rigs used in surface blast hole drilling. The large blast hole drills are electrically powered with high tension trailing cables linking the machines to the mine electrical network. Smaller drills, especially those using percussion in-the-hole drills, are not completely self contained, but are powered by compressed air from the mine air system.

The operator controls are situated near the tower, such that the operator can observe the drilling at all times. An optimum design places the operator in a safe position with all controls at his fingertips. The noise, dust, and vibration can be controlled by an environmental cab available with most large drills.

The drill steel rotation is accomplished by one of two methods. In the first method, the top-head drive rotates the drill steel by use of a motor/gear box guided up and down the tower. Rotary power for the top-head drive is provided by either direct current electric or hydraulic motors. Rotation speed should be adjustable from zero to about $125 \mathrm{rpm}$, enabling the driller to optimize drill performance. The rotation must also be slowed when coupling and uncoupling drill bits and drill rods to protect the threads. Also included in the rotary head is a pressure swivel, which allows the cutting removal fluid to enter the rotating drill steel.

h second method of providing rotation is the use of a kelly bar and rotary table. This system employs a mounted rotary table (gear) situated at the base of the tower. The rotary table has a splined, square or hexagonally shaped hole through its center. A kelly, a long steel bar shaped to mate with the hole in the rotary table, is used to transfer the rotary motion from the rotary table to the drill bit. As the rotary table turns, rotation is in turn transferred to the kelly. This method is commonly used for the large 
oil well drill rigs for deep drilling. The kelly is supported in a tower by a crosshead, which also contains the pressure swivel assembly.

Pressure provided to the drill bit is by one of four methods. Oil well rigs rely upon the weight of the drill string for down pressure. Because of the great depths encountered in an oil well, the weight of the drill string is normally much greater than the bit can withstand; therefore, oil well drills are designed to pull back rather than to force down. A second method, used on some large blast hole drills, involves an attachment to the tophead drive or cross-head of a rack and pinion gear set. A feed motor, integral to the rotary head, turns the pinion, thus moving the mechanism up and down the tower. A third feed mechanism involves a system of chains, or cables and pulleys, which moves the rotary head or cross-head up and down the tower. The power for this mechanism normally comes from aif or hydraulic motors, although some pull-down winches are connected directly to the prime mover via a prop shaftsgear-clutch arrangement. The fourth method for controlling the feed pressure employs the use of large hydraulic cylinders which apply force to the drill steel. As the cylinders provide one-to-one movement, a cylinder mounted inside the drill tower can only move the rotary head half the length of the tower. Therefore, a pulley arrangement which effectively doubles the movement of the cylinder is necessary to minimize tower height and maximize drill bit travel capabilities. In effect, the cylinder with a stroke of half the length of the tower would fit into the tower and still provide full movement of the rotary head. The hydraulic pressure is easily controlled in the cylinder; therefore, very accurate control of the movement of the rotary head is available.

\subsection{Characteristics of Drill Cuttings Removal Methods}

of consideration in selecting any rock drill is its method of removing drill cuttings. The four predominant cutting removal methods are:
(1) Air flushing,
(2) Water flushing,
(3) Augering;
(4) Bucket excavating.

The most common method for removal of drill cuttings is air flushing. All production blast hole drills, both surface and underground, rely on compressed air for both cooling the drill bit and removing the dxill cuttings. Compressed air travels through the drill stem and is exhausted up the drill hole. The volume of air necessary for removal of the cuttings is dependent upon the size 
and weight of the cuttings. To provide an efficient air flushing system, the annular area should be minimized. In particular, the drill steel should probably be at least 17 inches in diameter when excavating a 20-inch diameter hole. Since salt drilling is performed at a high penetration rate, a large amount of air would be necessary for cuttings removal, probably in excess of 1,500 CFM at 60 to $80 \mathrm{psi}$.

Water flushing is normally used in underground drilling for the smaller hole sizes. However, water flushing would not be a viable method for cuttings removal in rock salt, as the salt is very soluble. In order for water to be used, it would first have to be supersaturated with salt to minimize erosion of the hole during drilling. The salt water would be very corrosive, thus requiring all components of the drill in contact with salt or salt water to be constructed of bronze, stainless steel, or another corrosion resistant alloy. special chemicals may be added to the drilling fluid to assist in cuttings removal, but supersaturated salt solutions are usually still necessary to minimize hole erosion.

Continuous flight augers, used in conjunction with drag bits, are a common method of drilling large holes in soft formations. As the chip size is quite large when using drag bits, air or water flushing may be difficult. If moisture is present in the salt cuttings, the cuttings would tend to pack in the auger; this would complicate the drilling procedure by making it necessary to back the auger out of the hole every few feet to clean the cuttings away. Although dust problems are minimized using auger cutting removal systems, the addition of sections of drill steel is slightly more complicated as the auger drill steel sections are harder to handle than normal drill steel.

The bucket excavation technique used for cuttings removal is not a continuous system. The method employs a drag type cutting bit integral to an excavator bucket which is attached to the drill steel, as shown in Figure 2.3. As the drill steel is rotated, the cuttings fill the bucket and are removed by pulling the bucket from the hole and dumping it. To facilitate easier removal of the cuttings, the bucket may be hinged such that it can be opened, and the cuttings dropped into a load-haul-dump machine or anothez transport vehicle.

Except for the bucket system of drill cuttings removal, no other standard drill rig is availabie at this time which can transfer the drill cuttings directly into a shuttle car or similar haulage vehicle. since salt excavated from the canister emplacement holes must be removed from the repository, a means of 


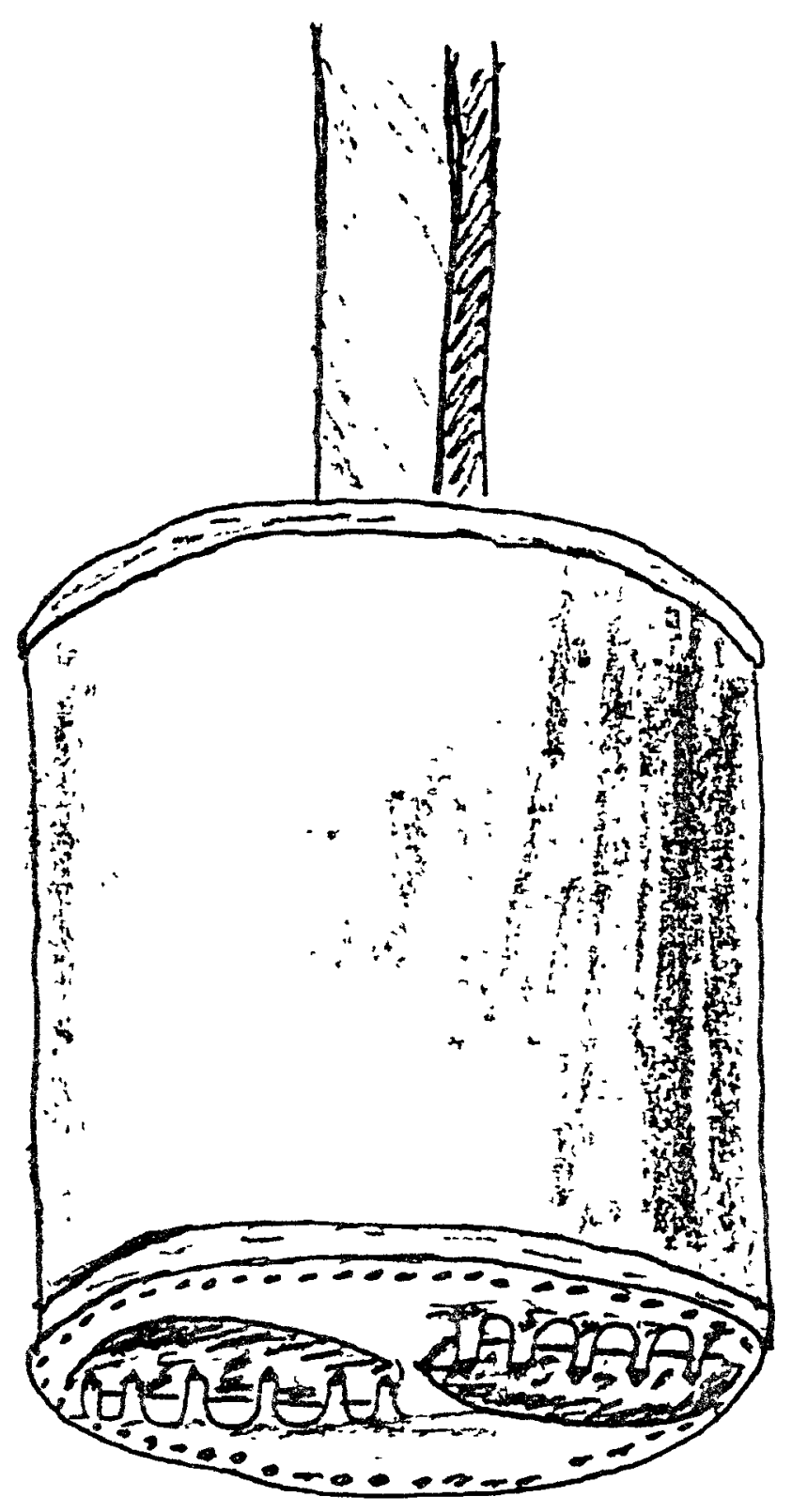

Figure 2.3. Bucket Excavator Attached to Kelly Bar with Drag Type Bits 
transferring this salt from the drill hole mast be provided. In normal blast hole drilling where there is only a small amount of cuttings to be removed, the excess is usually shoveled away from the hole by hand. The large amount of material excavated from these large holes would make hand shoveling impractical at best.

Several methods of drill-cuttings transfer could, however, be employed. The cuttings could be vacuumed away into special haulage cars, incorporating both cuttings removal and dust control in one machine. Also, a special conveyor system built into the drill itself could collect the drill cuttings at the top of the hole and carry them to the transport vehicle. Neither of these systems would require new technology, and could be built from standard components available off-shelf.

\subsection{Characteristics of Dust Control Methods}

Airborne dust must be controlled to within specific limits set forth by applicable regulatory agencies. A variety of methods are available which adequately control airborne particulates. The methods most applicable in underground mining are:

(1) Wet drilling,

(2) Water injection,

(3) Steam injection,

(4) Centrifugal separators,

(5) Bag separators.

The most common method for control of dust caused by drilling is to employ water as the hole cleaning fluid. Drilling large-diameter holes in rock salt would probably exclude wet drilling, as the hole erosion caused by the salt being dissolved in the drilling fluid would be unacceptable. Even a supersaturated salt solution would not guarantee the smooth holes necessary for canister emplacement, as the heat generated by the drilling would still cause a portion of the salt to go into solution.

The method of water injection into the compressed air for drill cuttings removal, binds the dust into fairly large particles which do not become airborne. Special detergents can be added to the water which increase the wetting ability, thus the efficiency of the dust suppression. Steam is also used to perform dust suppression and is employed when the amount of water used must be minimized. Steam disseminates more readily into the air stream, thus making it more efficient than water. 
Large surface drills usually use a vacuum system in conjunction with a centrifugal dust collector. A hood is positioned over the top collar of the hole and a large vacuum line is used to suck the smallex particles away. The dust-laden air is drawn through a centrifugal cyclone separator which removes the fine dust particles. Extremely fine dust might not be separated by centrifugal methods. However, a bag type collector would be an alternate means of dust removal, whereby the dust is sucked away from the drillhole and an initial coarse separation is performed by a centrifugal separator. Air containing the very fine dust then passes through a bag collector, which functions similarly to a vacuum cleaner, and the dust is filtered out in specially designed fabric bags. When the back pressure reaches a certain level, proportionate to the amount of dust that has been collected, a back blast of compressed air blows the dust off the bags, at which time it falls into a hopper. The dust can then be collected by depositing it into sealable or coverable containers. Moisture content is very critical when using bag type collectors, since too much moisture tends to clog the filter bags, making frequent bag replacement necessary. 


\section{DESCRIPTION OF DRILLING AS OBTAINED THROUGH INQUIRY TO MANUFACTURERS}

\subsection{General Remarks}

of the forty plus manufacturers of drilling equipment contacted, only elght supplied information concerning machinery that was applicable to the Alpha repository drilling task. Of these, none had equipment available "off-shelf" which could perform the drilling task; therefore, the equipment would require varying degrees of redesign and modification. If fairly extensive modifications were necessary, the drilling machine would, in all probability, become a "one-of-a-kind" prototype subject to all the shake-down troubles and spare parts availability problems which plague this type of equipment.

The market conditions of underground mining machinery place associated manufacturers in a position where they are not actively seeking one shot projects. In most cases, their manufacturing facilities and engineering staffs are both operating at near or full capacity, building standard lines of equipment. As result, very little interest was shown in developing a specialty drilling machine with only limited applications beyond that of the Alpha repository. On the other hand, the surface mining industry, especially coal strip mining, is in a state of flux due to environmental problems and proposed mining regulations. Sales and corresponding production of surface blast hole drilling equipment is down, which could place them in a position such that the design and fabrication of a specialty drilling machine would be a worthwhile enterprise.

In order to evaluate the drilling machines, manufacturers were requested to supply information describing their equipment which could perform the Alpha repository drilling task. Only a basic description of this task was given to each manufacturer in order that no type of arilling or particular machine would be initially screened out. Essentially, the manufacturers were requested to supply information on their drills capable of drilling 20 to 30 inch diameter holes to depths of 15 to 30 feet in rock salt where thin beds or lenses of a harder, anhydrite may be present. These holes were be to excavated in rooms having dimensions of a minimum of 22 feet wide and 16 feet high. Holes were to be drilled on a square or off set pattern with 4 foot center to center distance between holes and rows of holes, and a three foot minimum distance from the rib (wall) to the centerline of the adjacent holes. The main and sub-main haulageways were established to be a minimum of 20 feet wide by 26 feet high, with square entries 20 feet wide by 16 feet high into 
the storage rooms. Shaft and hoisting specifications were not indicated to the manufacturers in detail; however, it was stated that vertical shafts, as opposed to an inclined ramp, would be the means of access into the repository. The type of drill and any design/function details were left to the manufacturers discretion with the exception of suggesting that diesel power not be considered for the drilling cycle if other power sources were avallable. Initial inquiries showed only a very limited selection of drilling machines which could drill a 20- to 30-inch diameter hole. Therefore, an investigation was conducted to determine the availability of equipment which could perform the same hole drilling task for smaller hole diameters in the range of 15- to 20-inches. Even when the smaller hole size was considered, the selection of available drilling equipment was not enlarged significantly. This is not surprising, as the largest surface blast-hole drills are set up to excavate 15- to 17-inch diameter holes. This may seem contradictory, but these surface drills are extremely large and complicated and could never be adaptable to the Alpha repository drilling task. Underground machinery must be designed on a much smaller scale than the surface drilling equipment, due to the obvious size and weight limitations in most underground mining situations. Historically, underground mining equipment has been tailor made to the particular mine, with change and innovation following relatively slowly behind the more progressive surface mining industry. Only recently has the large blast-hole technique, used in the surface mining industries, been adapted to large scale underground mining methods. Two manufacturers of these small, underground blast-hole jumbos could provide equipment for drilling 5- to 7-inch diameter blast holes using in-the-hole percussion drills. Major modifications of the drill bit, drill rod, centralizers, tower, rotary head, and rod handling systems would make drilling the 15- to 20-inch diameter emplacement holes possible, although the penetration rate and reliability of the drill may be somewhat reduced.

In order to properly evaluate the various arilling machineries, specific information regarding the following items were requested from the manufacturers:

(1) General description of the drilling machines,

(2) Drilling principle;

(3) Power source and requirements;

(4) Method of cuttings removal;

(5) Methods of dust control if available;

(6) Traming method and expected velocities; 
(7) Drill performance including drill penetration rate and drill rod handling time;

(8) Bit and steel wear rate and replacement costs;

(9) Maintenance costs;

(10) Initial capital investment;

(11) Manpower requirements;

(12) Special features not generally common to standard drilling machines;

(13) Useable service life;

(14) Necessary or advised modifications;

(15) Capability of drilling through anhydrite beds.

For these 15 specific topics, no manufacturer was able to provide completely detailed information. For the most part, this is due to the lack of experience in drilling large holes in rock salt. The available equipment requires modification, to some degree, for compliance with the emplacement hole drilling task.

The information hereafter is unfortunately limited to that which has been already published for standard machines immediately available, and most of the detailed information involved "ballpark" estimates and extrapolations from similarly designed and utilized equipment.

\subsection{Acker Drill Company; Scranton, $P A$}

The Acker Drill Company proposed that a modified version of their model WA-1 rotary drill, as illustrated in Figure 3.1., be used for drilling the canister emplacement holes. This is a top head drive, rotary drill powered by dual hydraulic motors in the rotary head, where the high pressure hydraulic fluid is supplied by a variable displacement reversible hydraulic pump. The drill rotation is capable of four speed ranges, both forward and reverse ranging from zero to 34-70-125-266 RPM. Ten thousand foot-pounds of drilling torque at 34 RPM (6I horsepower) is used for drill rotation. The drill feed is positively controlied by dual hydraulic cylinders capable of providing 24,000 pounds of down thrust and 20,000 pounds of pull back force. This machine is designed to utilize a variety of rotary drilling techniques including arag and tricone bits with compressed air cuttings removal, drag bits with continuous flight auger cuttings removal, and a drag bit with a bucket excavator. The manufacturer recommends using drag bits and auger cuttings removal for drilling the rock salt. An attachment device which would cut the drill cuttings for transfer to an LHD machine or shuttle car is also suggested. Dust control can be provided through the installation of an opti- 
cal five horsepower, 1500 CFM centrifugal dust oollector. The chassis is a modified, rubber tired carrier which uses a hydraulic motor drive in place of the normal drive train. This hydraulic motor is powered by the same hydraulic pump used in the drilling cycle. Stablilation is provided by three hydraulic jacks which raise the chassis off the floor and are capable of wedging the tower against the roof. The main hydraulic pump which provides the high pressure hydraulic fluid for both tramming and drilling functions is driven by a 100 horsepower electrical motor. An additional feature is a powered cable reel capable of storing up to 350 feet of electrical cable.

This machine, as proposed, is so extensively modified that it should be considered for all intents and purposes a prototype. The chassis would require major modifications to provide a hydraulic drive and space for the large cable reel. The tower would require shortening to 14 feet 4 inches, to enable vertical drilling in the specified 16 foot high rooms. As the tower is wedged against the roof by the chassis stabilization jacks, additional strengthening of the tower would also be necessary. The other major components, power pack, rotary head and dust collector would be unmodified.

The information concerning costs of this machine was very sketchy. The original drilling machine was conceptually laid out in 1972 for a similar drilling project. The cost for the purchase was established at $\$ 150,000$. Cost data concerning maintenance, bits, and drill rod were not supplied by the manufacturer.

The drilling performance, drilling rates, set up time, drill rod handing time, etc. were not delineated by the manufacturer, except for an estimate of a production rate of one hole per hour for a 15-inch diameter hole to a depth of 30 feet.

The major portion of this design is sound; however, there are two problem areas which are evident. The first, is the size of the machine which limits its mobility. The length of the machine excludes turning perpendicular to the ribs (wall) of the storage rooms, thus limiting the distance from the rib to the centerline of the first hole at four feet. This would increase the overall size of the repository due to less efficient hole placement in the storage rooms. The second problem area concerns the lack of special equipment for handling the large, heavy sections of drill rod resulting in inefficlent maneuvering time and possibly dangerous operation.

overall, this is a well designed machine. However, a different chassis, probably crawler mounted, would provide a better utilization of the drili when considering the Alpha repository replacement hole drilling task. 


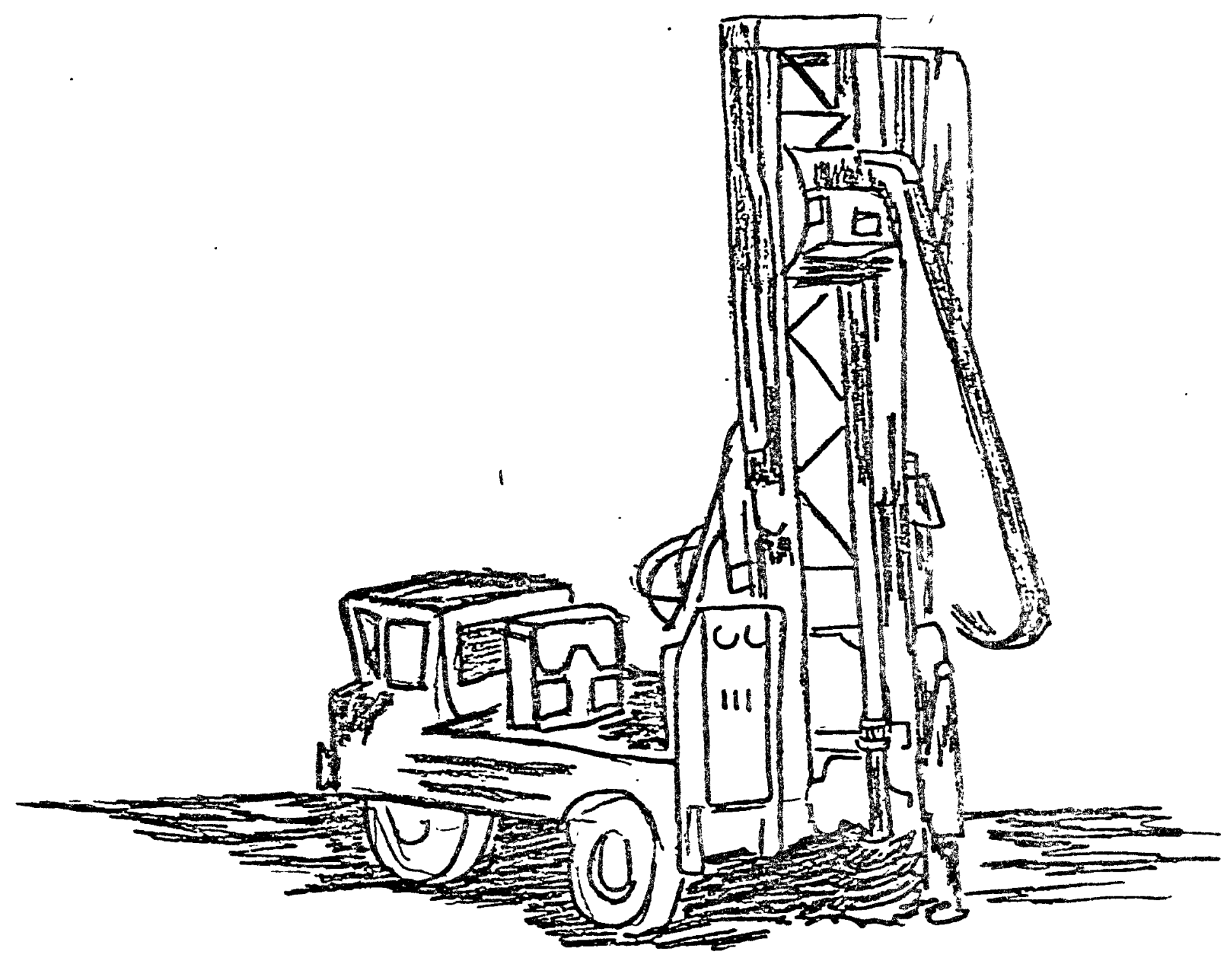

Figure 3.1. Truck Mounted, Top Head Drive Rotary Drill; similar to Acker Drill Company Model WA-I 
3.3. Calweld, Division of Smith International, Inc.; Santa Fe Springs, CA Calweld manufacturełs a large variety of drilling equipment and proposed a modified version of their Model $150 B$ rotary, bucket excavator drill, as illustrated in Figure 3.2. This machine is specially designed for drilling large holes in fairly weak materials. Excavation is effected by a drag/ blt bucket combination attached to a telescopic kelly, which is rotated by a large totary table, designed to permit the passage of a bucket up to 40 inches in diameter through its center. Normally, this drilling machine relies upon the weight of the bit and kelly to provide the proper amount of down force; however, in this application a winch operated "cable crowd" is available for providing additional down force. No additional drill steel is necessary as the kelly is built up of five telescopic sections which enable hole drilling to a depth of 30 feet. The hole diameter for this machine can range from a minimum of 12 inches to a maximum of 84 inches in diameter using special reamer blades attached to a 36-inch diameter bucket. The holding bucket, when full, is withdrawn from the hole through the central portion of the rotary table and swung away from the machine by a "dumping arm" mechanism. The bucket is then dumped by the hinged lower portion (which contains the drag type cutter bit) into a special conveyor system which would then transfer the cuttings into suitable haulage devices for removal from the repository. Every function on this machine is hydraulically actuated, with an electronic/hydraulic power pack containing a 100 horsepower electric motor, two variable displacement hydraulic pumps (one for the rotary table and one for the main winch), and one fixed displacement pump for operation of the hydraulic cylinders. Propulsion, (tramming) of this drilling machine is provided by "walking beams" which move the drill similarly to the giant walking drag lines used in the coal strip mines.

This machine requires relatively minor modifications to enable it to drill the canister emplacement holes. The tower must be shortened to clear the 16 foot room height and the kelly bar must also be shortened for the same reason. No major modification to the chassis need be considered, as it is compact and appears to be a very sturdy design.

Calweld furnished very specific cost details on initial price and operational expenses. The bare machine would cost $\$ 74,000$ plus an additional charge of $\$ 6,000$ for custom engineering. The five section kelly would cost $\$ 4,500$, and the 24-inch diameter, heavy duty bucket utilizing replaceable tungsten carbide tipped bit teeth would cost $\$ 1,600$. The optional pull down mechanism adds $\$ 2,500$. These costs, plus $\$ 200$ for the first set of carbide 
teeth, give a total cost of $\$ 88,800$.

Maintenance costs were estimated by the manufacturer to be $\$ 200$ for tooth replacement for every 90 feet of drilling, \$5,000 for replacement of the kelly every year, and $\$ 4,500$ to $\$ 5,000$ for miscellaneous costs (oil, grease, hydraulic ine replacement, etc.) every year. The inftial spare parts stockage would be approximately 10 percent of the initial purchase price according to the manufacturer.

This machine should be able to drill a 30-inch diameter hole to a depth of 30 feet in less than $1 \frac{1}{3}$ hour without using a pull down mechanism according to the manufacturer's statement. This would include set up time and removal of the cuttings from the drilling area. Drilling a smaller hole utilizing the pull down mechanism, holes should be drilled in less than one hour. The thin beds of anhydrite would cause slightly slower penetration rates, but would not adversely effect the overall drilling.

This drilling machine may be well suited to the emplacement hole drilling task. Three problems could be associated with this machine. The first, a relatively minor problem, concerns the lack of any dust control system. This of course, could be added easily. The second problem concerns the alignment accuracy of drilling the large diameter holes on four foot centers to depths of 30 feet. However, the 15 foot deep holes would probably not pose any serious problems in this regard. The third problem involves the muck removal system wherein the mechanism which swings the bucket away from the drill for dumping only moves to one side of the machine. This would prove impractical when drilling along one rib of the storage room.

This seems to be a well thought out machine and would warrent close consideration when choosing the drilling equipment for the Alpha repository.

\subsection{Cyclone Drill Company; Orrville, $O H$}

The Cyclone Drill Company manufactures drilling equipment for specialty applications. A preliminary report from Cyclone suggests that the emplacement holes be drilled with a modified version of their standard TH-100 truck mounted rotary drill which would be similar to the machine illustrated in Figure 3.1. The drill steel rotation is provided by a hydraulically powered rotary head. The manufacturer suggests using a reverse circulation cuttings removal system, whereby the top of the borehole is sealed off and compressed air is forced down the annular area formed by the wall of the hole and the drill steel. This air then enters the drill steel at the bit end, entrafning the dust and cuttings and carrying them to a collector system on the truck 


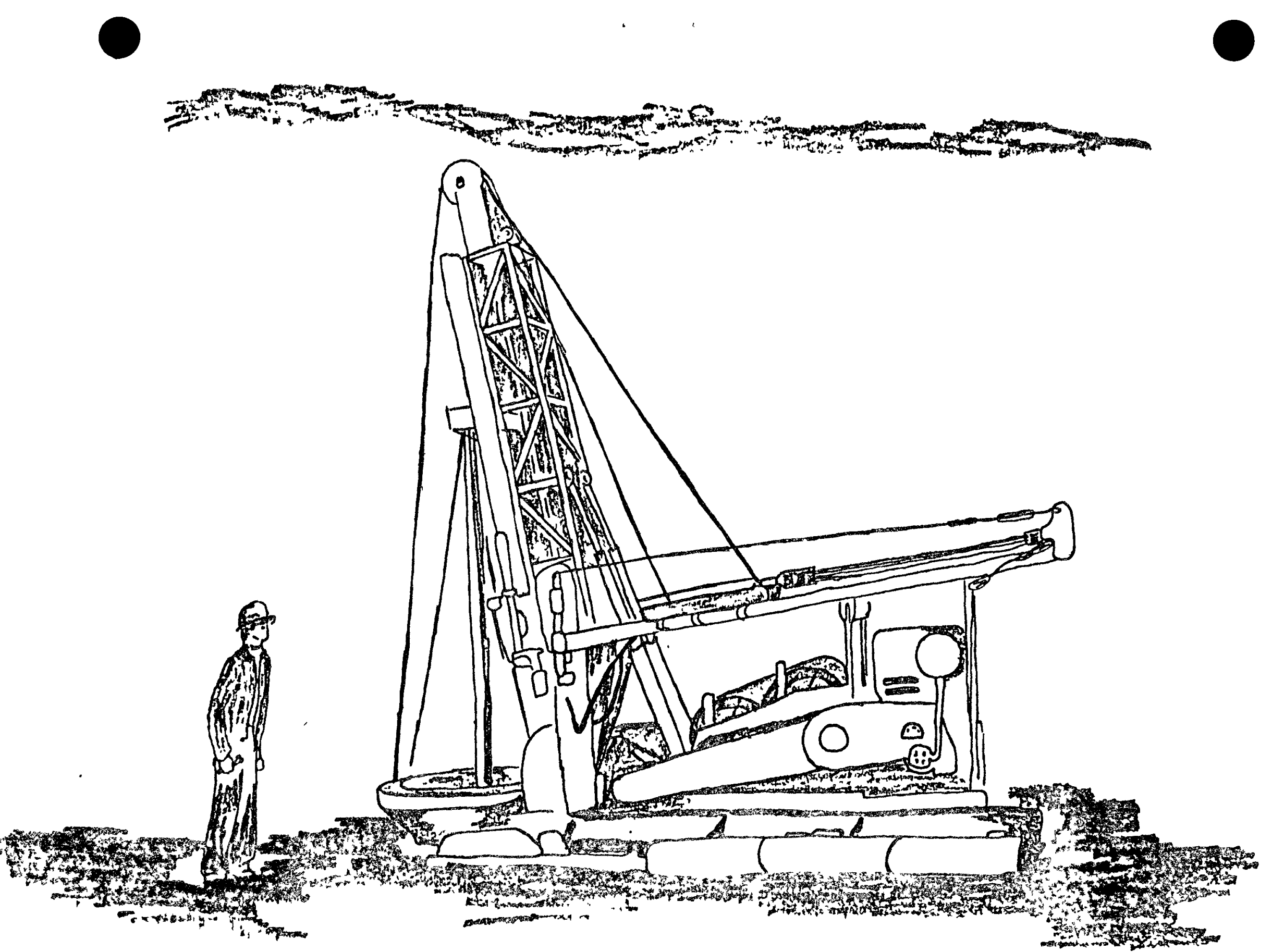

Figure 3.2. Bucket Excavator, Rotary Drill with Extendable Kelly and Rotary Table; similar to Calweld, Division of Smith International, InC. Model $150 \mathrm{~B}$. 
chassis. This method of cuttings removal minimizes the amount of compressed air necessary when drilling extremely large holes.

The manufacturer supplied no explanation of the type or rating of the power system for their proposed machine. The surface drills of the manufacturer are normally equipped with diesel engines for driving the hydraulic pump and air compressor. Normally, machines of this type would require approximately 100 horsepower for driving the rotary head and auxiliary equipment, plus 150 horsepower for the air compressor.

This machine would have to be designed from the ground up to make it applicable to the Alpha repository hole drilling task. Very few components would remain unchanged; thus, the finished product would be a prototype drilling machine. The Cyclone Drill Company is set up to do custom engineering and, undoubtedly, a quality finished product would be expected. However, no prototype can be expected to perform at its optimum without a long field trial and up date modification.

The performance criteria for the $T H-100$ drill was not given by the manufacturer. They had no experience drilling large holes in rock salt, although they were certain that it was capable of drilling 20-inch diameter holes to depths of. 30 feet with no serious problems. They had no estimate of the associated time constraints for changing drill rods, movement between holes, set up and take down, and other time consuming functions. This was again the result of this being a prototype drilling machine.

No firm cost estimates were developed, but a "ballpark" amount of $\$ 175,000$ was given. The drill bits are not manufactured by the Cyclone Drill Company. However, Reed Tool Company, Houston, TX, could supply a 22-inch diameter hole expanding bit used in conjunction with a standard $97 / 8$-inch diameter standard tricone bit. The total cost of the drill bit/hole expander combination would be about $\$ 7,300$. However, the $\$ 4,200$ body which mounts the replaceable cutter bits in the enlarger mechanism is not repurchased when changing cutter bits.

The lack of specific information makes the analysis of this machine difficult. The application of reverse circulation cuttings removal would require further study for this particular machine.

\subsection{The Robbins Company; Seattle, WA}

The Robbins Company prepared a fairly complete proposal package for a track mounted version of their model 110 rotary drill with modifications to enable drilling 20-inch diameter holes. This machine is illustrated in Figure 
3.3. The standard $I I D$ drill is set up to excavate vertical or slightly angled holes up to $12 \frac{3}{4}$ inches in diameter with conventional tricone or drag bits. The rotation is controlled by a hydraulically activited rotary head capable of producing constant rotation at up to $2740 \mathrm{ft.-Ibs.} \mathrm{of} \mathrm{torque} \mathrm{or} \mathrm{with} \mathrm{break}$ out torques of up to $10,800 \mathrm{ft} .-1 \mathrm{bs}$. The chassis is a sturdy crawler design which would have a drill rod handling system for positioning the heavy sections of drill rods. The crawler tracks are driven by air motors with the compressed air being supplied from the mine air systems through a "bull hose". The cuttings removal is controlled by compressed air carried down to the drill bit and out the annular area between the hole wall and the drill rod. To minimize air requirements, Robbins suggested using a 19-inch diameter drill rod for annular area minimization. According to the manufacturers experience, the salt dust created by drilling would be objectional and suggested a vacuum type dust collection system which would suck the dust and cuttings away, storing it in a holding device for consequent removal from the repository. To enable accurate hole drilling, the manufacturers suggested using optional roof jacks which would position the machine between the floor and the roof of the storage rooms.

The main hydraulic pumps are driven by a 75 horsepower electrical motor with no provisions for a take-up reel for the electrical cable. The compressed air for traming and hole cleaning is supplied from the mine air system, and probably about 150 horsepower would be required for producing this compressed air.

In order to drill 20-inch diameter holes, the manufacturer stated that modifications would be necessary to the main frame, rotary head, centralizer and drill rod handling system. These modifications were necessitated by the use of a much larger drill rod which would be fabricated especially for this application.

The cost of the basic drilling including the electric/hydrauizc power pack is $\$ 118,000$. Six sections of the special drill rod would cost an additional $\$ 30,000$ plus a $\$ 5,000$ drill bit. The special air powered, crawler chassis would cost an additional $\$ 60,000$ which gives a total price of $\$ 213,000$. The dust collection system, which could be obtained from another source, would cost $\$ 40,000$ according to Robbins. The cost of the basic drill pilus the dust collecting system would then total over a quarter of a million dollars. The manufacturer was unable to provide an estimate of the maintenance cost.

The manufacturers stated that penetration rates for drilling 20-inch diameter holes would average one foot per minute. The time to add the 


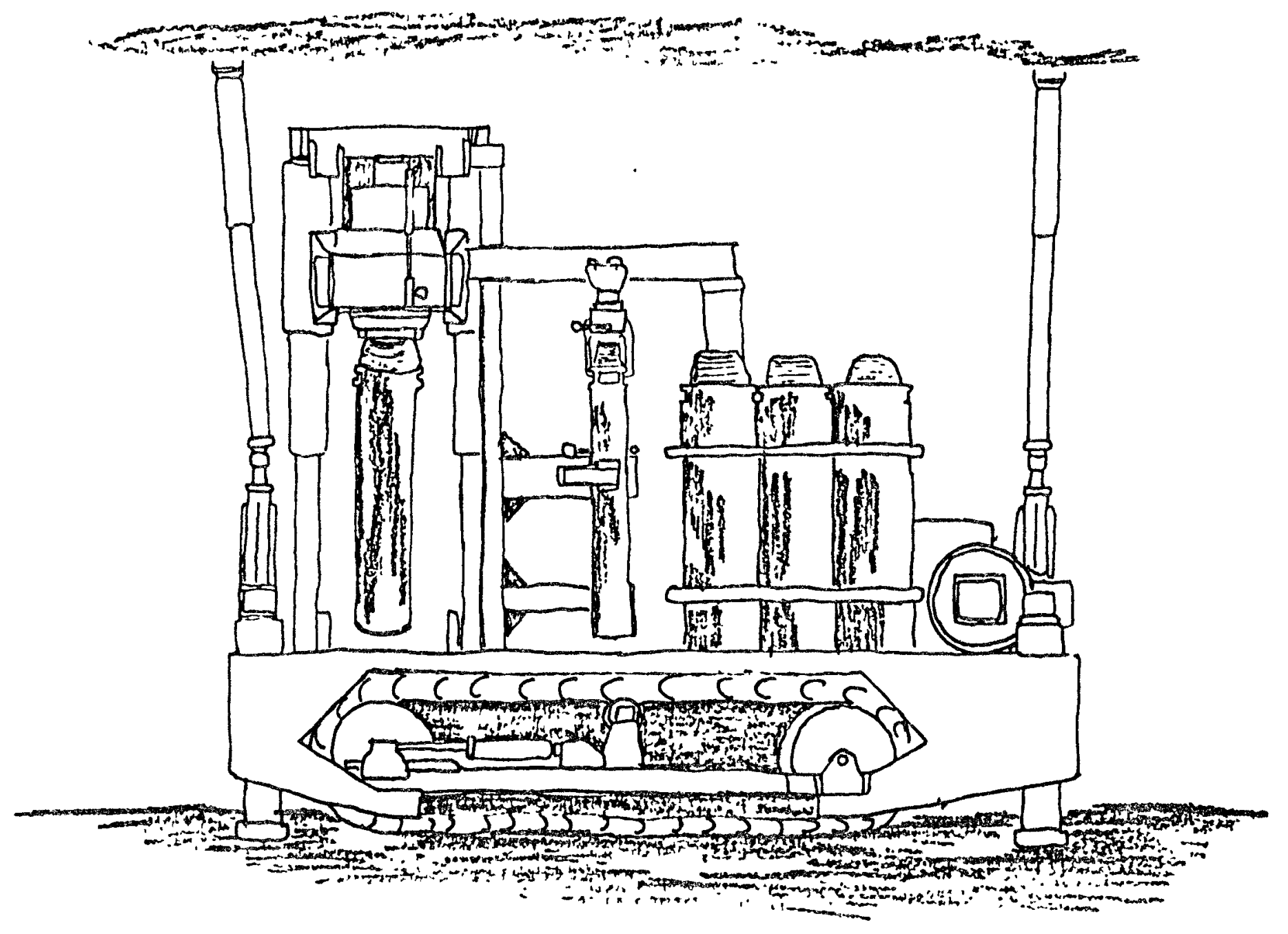

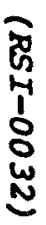

Figure 3.3. Crawler Nounted, Top Head Drive Rotary Drill with Roof Jacks and Drill Rod Handling

Nechanism; similar to the Robbins Company

Model $11 D$. 
additional drill rod for a 30 foot hole would increase the drilling time to 40 minutes. The drill could be moved from one hole to the next and set up for drilling in approximately 40 minutes, which would give an overall production rate of 1 hour and 20 minutes for each emplacement hole.

This is a well designed machine, engineered by a company which specializes in underground mining machinery. The Robbins personnel stated that the drill as presented would work well; however, a more detailed analysis of the drilling task and the preferences of the personnel in charge of the drilling would provide a greater insight into the anticipated drilling problems, possibly resulting in design changes for increased productivity.

\subsection{Schramm Inc.; West Chester, PA}

Schramm Inc., manufacturer of a variety of surface drilling equipment, suggested using their model $X 4016$ rotary drill, as illustrated in Figure 3.4. This machine was designed to drill 16-inch diameter holes for emplacement of the long elevator control cylinders. The drill is skid mounted on a very simple frame with no apparent stabilization system. Rotation is hydraulically controlled using a top drive rotary head capable of 100,000 inch pounds of torque. The electric/hydraulic power pack is skid mounted and remote from the main drill. The drilling is set up for auger cuttings removal only, with no provisions for air or water hole cleaning.

No specific information was received concerning the performance and optional features available for this drill. The drilling rate would be considerably lower than the other rotary drills because of long set up times as a result of the skid mounting. Due to the simplicity of this machine, the initial cost of $\$ 40,195$ is comparatively low. The machine is not well suited to the canister emplacement hole drilling task without major modifications.

\subsection{Dresser Industries, Inc.; Dallas, TX}

Dresser Industries, Inc., a major supplier of large tunneling and raise boring equipment, also manufactures a line of core drilling machinery. They suggested using their model BBS-15, Boyles Core Drill, which would be equipped with an optional electrical drive, as illustrated in Figure 3.5. This machine is equipped with a twin cylinder hydraulic feed and a hydraulic chuck. Also included would be a winch, capable of lifting 8,000 pounds. To drill 20-inch diameter holes, the manufacturers suggested using a speciai tungsten carbide faced coring bit with a 3 foot core barrel. To minimize the dust problem, they also suggested using reverse circulation, compressed air cuttings renoval, 
whereby cuttings would be removed through the hollow drill rod and then separated using a centrifugal dust collector. The core would be brought out in three foot sections, which could be broken away from the parent rock easily according to the manufacturer.

Although electrically driven machines of this type have been built previously, the manufacturer gave no indication as to the power requirements. Their standard diesel and gasoline driven BBS-15 has horsepower ratings of 26 through 37 horsepower, depending upon the make of the engine. It was assumed that the electrical power requirements would fall somewhere within this range.

To enable drilling of the large canister emplacement holes, no modifications would be made to the basic drill; however, a chassis with a hoisting mast and stabilization and positioning jacks would have to be fabricated. In addition, a dust collection system would have to be developed, utilizing either standard re reversed flow cuttings removal with compressed air.

The cost of this drilling machine is much lower than the larger and more complicated rotary drills. Base price for the BBS-15 Boyles coring drill is about $\$ 25,000$. As the drill bit mist be specially designed, the manufacture's estimate indicated a purchase price of $\$ 5,000$ per bit and core barrel combination. No figures concerning bit and drill rod service life were given. Also information was not available for maintenance costs of the basic drilling machine, but the simplicity of design and small power requirements would make maintenance costs relatively low in comparison to the large blasthole, rotary drills.

Very rapid penetration rates could be expected in rock salt, with only slight decreases when drilling through the beds of anhydrite. The Dresser personnel predicted that penetration rates of one foot per minute would be probable, while removal of three-foot long core sections would take from six to ten minutes each; hence, the hole production rate would range from one hour and 30 minutes to 2 hours and 10 minutes per hole, not counting set up time. Core drilling is undoubtedly a reasonable method for drilling the rock salt. $A$ Dresser coring drill is currently being employed to drili 20-inch diameter holes to depths of 20 feet in slate with an unconfined compressive strength of about $8,000 \mathrm{psi}$. Two major problem areas seem to exist. The first being the removal and handling of the large sections of salt core; a three foot core, 18-inch diameter would weigh about 700 pounds. The removal of the fine dust created by drilling would also be a najor probiem. In order to utilize core drilling, these problem areas would have to be solved. 
Figure 3.4. Skid Mounted, Top Head Drive, Rotary Drill with Remote Electric/Hydraulic Power Pack; similar to Schramm, Inc. Model X4016.

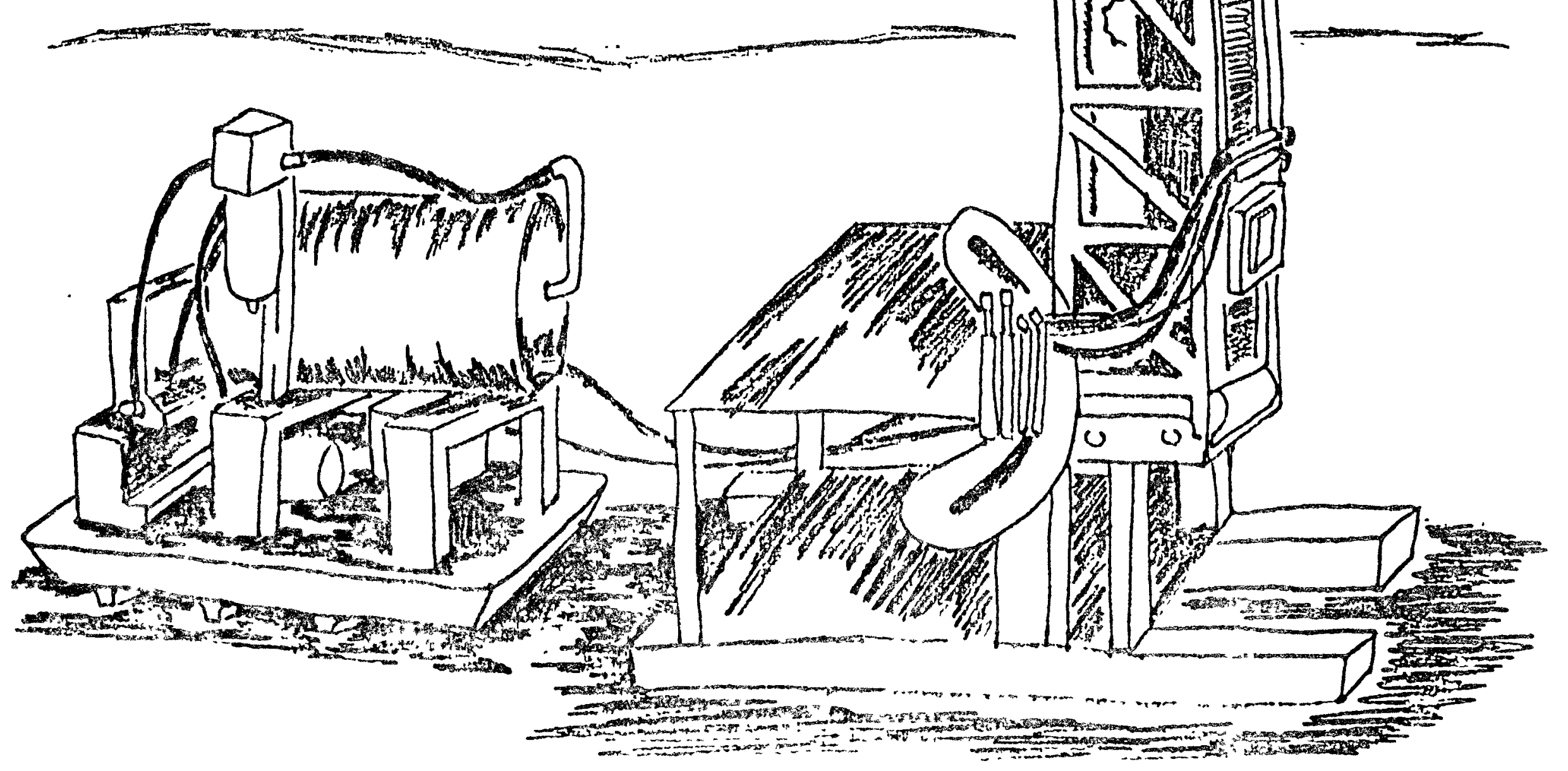




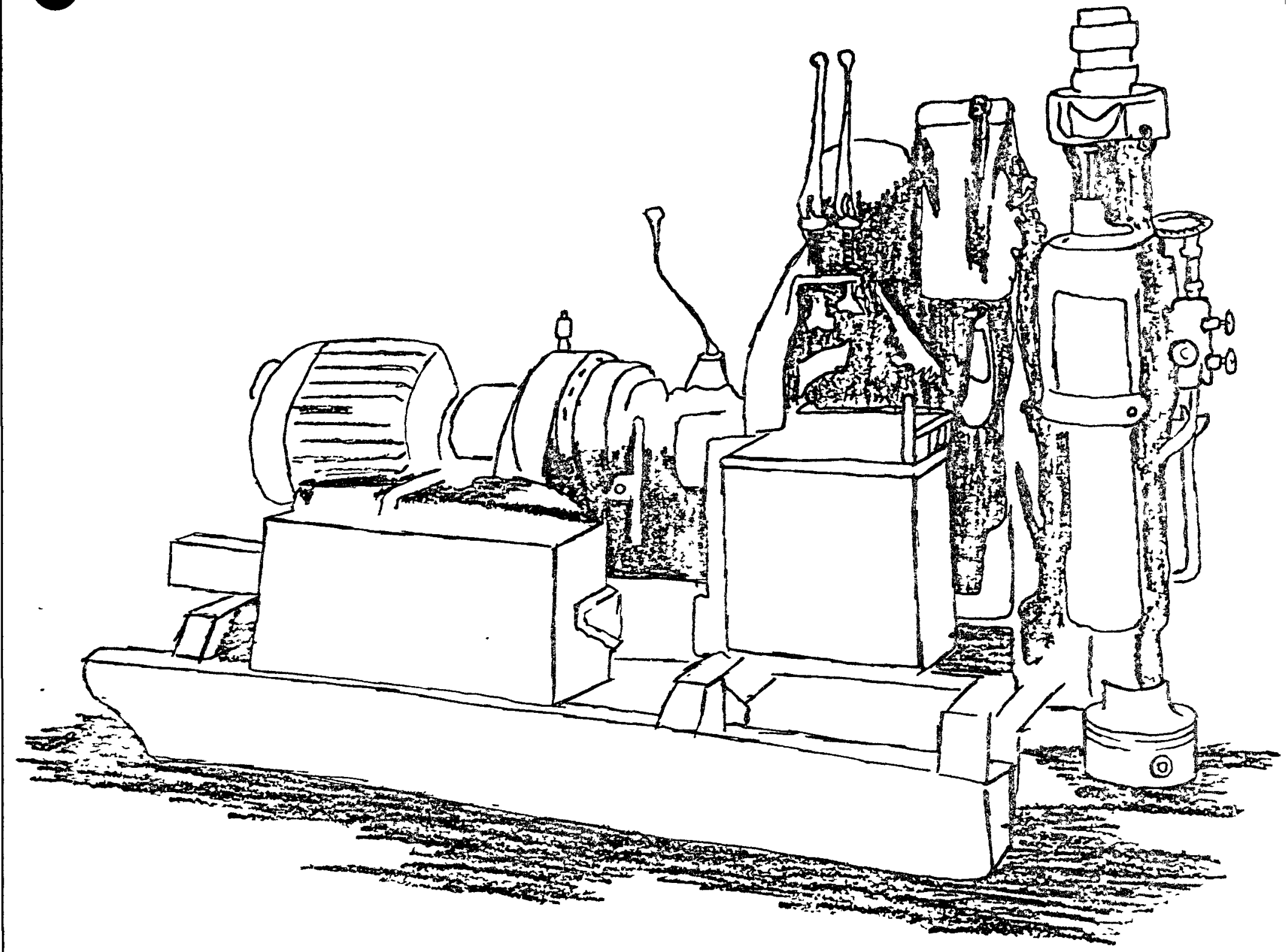

Figure 3.5. Sma11, Electrically Powered Core Drill; similar to Dresser Industries, Inc. BBS-15 Boyles Core Drill. 


\subsection{Ingersol1-Rand Company; Seattle, WA}

Ingersoll-Rand proposed using a modified version of their CMM/DHD blast hole drill as illustrated in Figure 3.6. This is a small crawler mounted drilling machine using an in-the-hole percussion drill. This machine is potentially capable of drilling only the smaller range, 15 to 20-inch diameter, emplacement holes. The machine does not carry its own compressor, but relies upon the mine compressed air system for power. The drill feed, rotary head, and tramming functions are hydraulically operated with the hydraulic pump driven by a 14 horsepower air motor. The machine is stabilized by four hydraulic jacks, three mounted on the chassis for leveling the machine, and one on the tower which is forced against the roof to firmly wedge the machine in place while drilling. As with all percussive in-the-hole arills, the cuttings are removed by the same air that operates the drill. A special option is a small compressed air operated pump which meters water into the drilling air, thus controlling the dust to some extent.

No power consumption details were available for the CMM/DHD. However, the large DHD-16 in-the-hole drill requires at least $300 \mathrm{CFM}$ of air at 100 psi to operate at maximum efficiency. Additional hole cleaning requirements could increase these air consumptions to about 600 CFM. The air motor which operates the main hydraulic pump requires at least 350 CFM at 100 psi. Thus the total compressed air requirements would be 950 CFM at 100 psi which corresponds to approximately 200 horsepower.

This machinery would have to be extensively modified for drilling the 15 to 20-inch diameter holes. The major modification would involve increasing the diameter of the drill steel to decrease the annular area between the drill steel and the wall of the borehole to insure proper hole cleaning. Due to this modification, the centralizer, rotary head and drill rod handling tools would also have to be modified. As no large drill bits are available for use with the CMM/DHD in-the-hole percussion arill, a custom arill bit would also be required.

No accurate estimate of the cost for this machine was received, but a "ballpark" figure of $\$ 65,000$ was provided in a telephone conversation.

Ingersoll-Rand has very limited experience in drilling large holes with this class of drilling equipment. They have used a similarly modified blast hole drill to excavate 18-inch diameter boreholes, but performance and operational costs were not available.

This machine is well designed for blast hole drilling and underground mines as it is compact and reliable; however, the problems associated with 


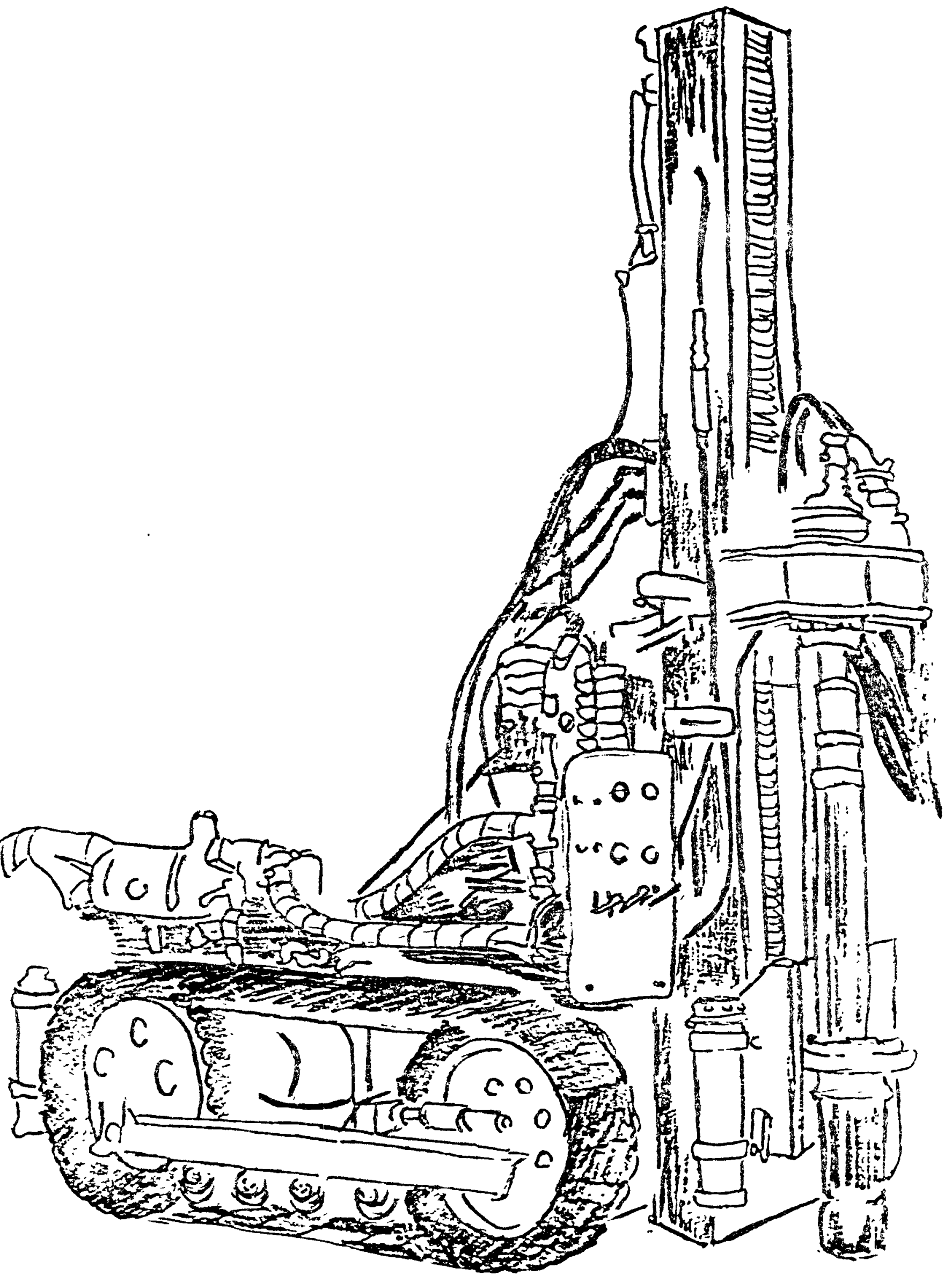

Figure 3.6. Small, Crawler Mounted Percussive Drill; similar to Ingersoll-Rand CMM/DHD. 
using it to drill holes over $800 \%$ larger in area than it was initially designed for would probably cause reliability problems in the chassis and the drill itself. The dust created by the percussion drilling (even if water is injected into the air stream) could also create problems. In sumary, this drill would not be a good choice for the Alpha repository emplacement hole drilling task.

\subsection{Atlas Copco, MCT AB; Sweden}

Atlas Copco manufacturers a small, crawler mounted blast hole drilling machine for use with percussion, in-the-hole drills. This machine is very similar to the one manufactured by Ingersoll-Rand which is illustrated in Figure 3.6. The Atlas Copco machine is capable of drilling holes to 12 inches in diameter without modification. The manufacturer felt that a special bit and larger drill rod would enable drilling holes up to 15 inches in diameter without major problems.

No major cost/performance breakdown has been received; however, the base price of an unmodified machine would be about $\$ 55,000$, depending upon the options chosen. The manufacturer estimates that a specially designed drill bit would cost in the neighborhood of $\$ 6,000$.

The Atlas Copco and Ingersoll-Rand small blast hole drilling machines are almost identical, although Atlas Copco manufactures a slightly larger in-the-hole percussion drill which would enable a greater penetration rate. 
4. DRILI SYSTEM PERFORMANCE AND COST SIMULATION

\subsection{Specifications and Assumptions for Large Hole Drill Simulation}

When analyzing the drill systems, several specifications and assumptions

were considered. These considerations are all based on information provided by Reference 1. The specifications used for analyzing the drill systems included :

Hole Diameter: 15 and 20 Inches

For the basic cost and performance simulation analysis, a 20-inch diameter hole was used. A 20-inch diameter hole would leave at least a 4-inch annular opening for the 10 or 12-inch diameter canisters. A simulation of a 15-inch diameter hole was also done for the in-the-hole Percussion Drill.

\section{Hole Depth: 15,25 , and 30 Feet}

Cost and performance analyses were made for a 15 foot deep hole considering one canister per hole, and for hole depths of 25 and 30 feet considering 2 canisters per hole. For a canister length of 10 feet, the 25 foot hole would allow 5 foot of fill above the two canisters. The 30 foot hole was considered as the maximum depth given in Reference 1.

\section{Hole Spacing: 4 Foot on Center}

All analyses were made with the assumption that the canister emplacement holes will be drilled 4 foot on center. This is considered to be the minimum spacing for 20-inch diameter holes and depending upon the drilling drift associated with a particular drill, the distance should possibly be doubled. An increase in the hole spacing distance would increase both the tram time between holes and the total tram time between rooms and panels, due to the increased distance between the holes and the larger number of rooms and panels. The tram times account for between 7 and 17 percent of the total drilling time, depending on the drilling system and the number of canisters per hole.

\section{Hole Pitch: Square Pattern}

The arrangement of drillholes in a square pattern allows for more holes per room than a txiangular pattern. A square pattern arrangement was used for the cost and performance analyses; however, as with hole spacing, only tram time between holes and the total tram time between rooms and panels would bo affected by a different assumption. A triangular hole arrangement would increase the mine size by approximately 6 percent. 
Rib to Drill Hole Clearance: Minimum of 3 Feet to Centerline of Drill Hole

All of the drills considered are capable of drilling 20 foot deep holes with the center situated three feet from the rib. However, most of the drills would have to be positioned perpendicular to the normal direction of travel in order to drill a hole three feet from the rib. This would significantly increase the positioning time for the holes along the rib, and it is suggested that holes be spaced far enough from the wall to allow for drilling without realignment of the drill.

\section{Room Back Height: 16 Feet}

All drills potentially applicable to the drilling task, except one, were capable of being modified to fit into a room with a 16 foot high roof. The modifications to fit the drills into the rooms has been done before on most of the drills. The only drill which would not fit in a 16 foot high room was a rotary drill with a 20 foot mast, which appeared to have no advantages over the other available rotary drills.

\section{Accessway width: 20 Feet}

None of the drills considered to be applicable to this large hole drilling project exceeded 20 feet in width.

\section{Number of Holes: 50,114 to 144,305}

The number of canister emplacement holes depends upon the diameter of the canisters and the number of canisters per emplacement hole. A minimum number of holes, 50,114, would be required if two 12-inch diameter canisters were placed in each hole. The maximum number of holes required would be 144,305 if one 10-inch diameter canister was placed in each hole. The cost and performance analyses were done for both the maximum and minimum number of holes. Canister arrival rates were used as supplied by Reference 1.

Rock Type: Halite (approximately 97\% pure), with impurities dispensed and few stringers of shale or anhydrite greater than 0.1 inch. Unconfined compressive strength less than 6,000 psi

The estimates of drilling rate, bit wear, and machine size are based on the above description of the rock. All cost and performance parameters are based on the infrequent presence of 6 to 8 -inch thick beds of anhydrite as discussed in Reference 1.

Room Availability: Supplied by Mining Simulation Program 
simulation of the Snowflake Repository. This conceptual repository layout is discussed in Reference 2. The mining simulation output included, among other things, the year and date that each room became available for drilling. For the smallest repository in terms of excavation tonnage, which considered 12-inch diameter canisters, two per hole, an excavation rate of 275 tons per day was used. The largest repository in terms of excavation tonnage, which considered 10-inch diameter canisters, one per hole, was simulated using an excavation rate of 720 tons per day. These excavation rates were used to allow for the mining of the repository to be completed one or two years before the end of the canister emplacement.

Many of the drilling systems considered were modifications of existing units, and none of the drills have ever been used in a salt mine for drilling large diameter holes. Because the drills have not been used in applications similar to the underground large hole drilling, it is with caution that the performance and cost information is considered. The input parameters to the drilling simulation are estimates provided by manufacturers of the type of equipment simulated, or obtained from the staff of RE/SPEC InC.

The input parameters for each drill system are given in Tables 4.1 through 4.5. Simulation parameters which are common to all of the drill systems are not given in these tables, but are included in the example simulation in Appendix $A$.

\subsection{Description of Simulation Program}

Appendix $A$ is an example of the output from the dxill cycle simulator, displaying the cost and performance data for the Calweld Model 150-B Bucket Drill. All of the general input parameters necessary to simulate the drilling cycle are given in this example, along with the values specific to the Bucket Drill.

The drill simulation program operates by cycling through every day of each year of mine operation, determining the type of drill operation for each shift of each day. The drill rig may either be in production, maintenance, transit, or unscheduled downtime. The drill operation on a particular day determines what modifications will be made in the output parameters, such as percent of drill operation, idle drill days, number of available holes, and costs. Several of the costs factors are determined yearly, based on the number of drills operating during that year and the percent of actual drill operation.

\subsection{Simulation Results}

For each type of drilling system, a Nonte Carlo optimization technique was used to determine the optimum number of drills needed to produce the 
required number of emplacement holes for the upper and lower limits on the number of canisters per hole. For each system, only one drill was used for the first two or three years to allow the drilling contractor time to work out initial operational problems and to arrive at a better estimate of drilling performance characteristics.

Initial simulation runs were performed assuming a continual increase in the number of drilling units after the first two or three years in order to match the exponential arrival of the canisters. However, this approach was replaced by the utilization of all the necessary drills after the first two or three years, since a constant increase in drilling personnel and maintenance support facilities would be impractical. In other words, after the initial two or three year test period, the total number of drills necessary to complete the entire drilling process is utilized. This procedure did not cause any of the drills to stand idle during the first ten years while waiting for rooms to be mined. The capital cost flow and large equipment worth at the end of the project, which would result from yearly purchases of equipment with at least a 10 year life, also support the idea of a constant drilling rate after the first few years.

Table 4.6 displays a summary of the simulation results for five different drilling systems. These data are best reviewed on the basis of the cost ranges which are expected, rather than on a specific cost comparison of the drilling systems. Comparisons should not be made unless more accurate performance parameters are obtained. The costs are arrived at using 1975 base dollars and considering an eight percent interest or investment rate.

The number of holes given in Table 4.6 is sufficient to store the 12-inch diameter canisters, two canisters per hole. As can be seen in this table, the differences in the time required to drill one hole for each drill is not proportional to the differences in the maximum number of holes per day for each drill system. This is due to differences in drill set-up and take-down time and the time required to move the drill from one hole to another. Total project costs for the lower limit of 12-inch diameter canisters, two canisters per hole, range from 6.7 million to 12.0 million dollars. The lowest cost in Table 4.6 is for the in-the-hole Percussion Drill, but it is not 1ncluded in this range because it applies only to 15-inch diameter holes. For comparison purposes, the number of canisters was estimated for 7-inch diameter canister. Considering the same volume of cladding waste, 147,250 canister emplacement holes 30 feet deep would be required if canisters with diameters of seven inches were utilized. A 7-inch diameter canister was selected to allow for a 4-inch annular 
opening in a 15-inch diameter hole. A total drilling cost for the in-the-hole Percussion Drill drilling 15-inch diameter holes would be approximately 12.6 million dollars.

Table 4.7 displays dxilling cost comparisons for the lower limt of 12-inch diameter canisters, two canisters per hole and the upper limit of 10-inch diameter canisters, one canister per hole. The cost increase for the core drill from the lower to the upper limit was $170 \%$ and the increase was 179\% for the Bucket Drill. The inequal increases are due to the differences in set-up time, take-down time and tram time for the drilling systems. By applying the average increase to the values in Table 4.6 , the total drilling costs for the upper limit range from $\$ 18.3$ million to $\$ 32.9$ million dollars.

\subsection{Contractor's Estimate Compared to Simulation Results}

As a result of personal communications with MCKinney Drilling Company of Gainesville, Virginia, regarding the drilling requirements for the Alpha repository, McKinney submitted a budget estimate for the entire drilling task. Their estimate was based on 175,000 holes, 22 inches in diameter and 22 feet deep. Although these assumptions differ from those used in arriving at the results in Tables 4.6 and 4.7 , the results should be similar considering that the volume of salt removed from a hole with a diameter of 22 inches and a depth of 22 feet is only slightly more (6\%) than a hole with a diameter of 20 inches and a depth of 25 feet. The difference in the number of holes used in the MCKinney estimate should not significantly affect the drill cost per hole, since, as shown in Table 4.7, the cost per hole drops only slightly as the number of holes increase. MCKinney Drilling Company would utilize auger drills and they estimate their total cost at $\$ 34,603,000$ for 175,000 holes or $\$ 197.73$ per hole. This cost estimate is expressed in 1975 dollars and does not include overhead or profit for the contractor. 


\section{TABLE 4.1}

DRILL SIMULATION INPUT FOR

BUCKET EXCAVATOR, ROTARY DRILL

1. Drill Penetration Rate 0.6

(feet per minute)

2. Drill Steel Needed

(feet drilled per addition)

3. Drill Steel Addition Rate

(minutes per addition)

4. Drill Steel Subtraction Rate (minutes per subtraction)

5. Removal of cuttings (minutes per foot drilled)

6. Set up Time (minutes at each hole)

7. Make Down Time (minutes at each hole)

8. Tram Time Between Holes (minutes)

9. Cost of Drill Steel (per replacement)

10. Number of Holes before Drill

Steel Replacement

11. Cost of Drill Bits

$\$ \quad 200.00$ (per replacement)

12. Number of Holes before Drill Bit Replacement

13. Cost of Power (cents per kwh)

14. Power Consumption per hour (kw)

15. Machine Purchase Price

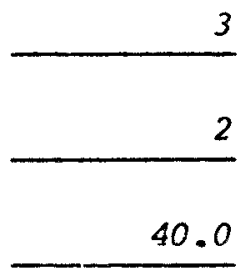

$\$ 88,800.00$

The input values numbered 1, 2, 3, 4, 9, 10, 11, 12, 14, and 18 were supplied by Calweld Division of Smith International, Inc., Santa Fe Springs, CA which manufactures a Bucket Excavator, Rotary Drill (See Section 3.3). All other input values were estimated by the staff of RE/SPEC InC. 
TABLE 4.2

DRILL SIMULATION INPUT FOR

\section{CORE DRILL}

1. Drill Penetration Rate

(feet per minute)

2. Drill Steel Needed

(feet arilled per addition)

3. Drill Steel Addition Rate

(minutes per addition)

4. Drill steel Subtraction Rate

(minutes per subtraction)

5. Removal of cuttings

(minutes per foot drilled)

6. Set Up Time

(minutes at each hole)

7. Take Down Time

(minutes at each hole)

8. Tram Time Between Holes

(minutes)

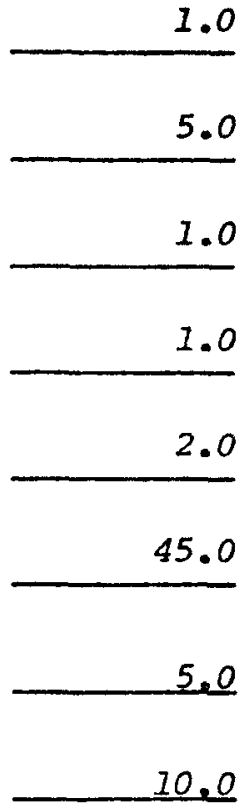

9. Cost of Drill Steel

$\$ 5,000.00$

(per replacement)

10. Number of Holes before Drill

5,000

Steel Replacement

11. Cost of Drill Bits

(per replacement)

$\$ 5,000.00$

12. Number of Holes before Drill Bit Replacement

13. Cost of Power

(cents per kwh)

14. Power Consumption per hour (kw)

50.0

15. Machine Purchase Price

$\$ 30,000.00$

The input values numbered 1, 2, 5, 14, and 15 were supplied by Dresser Industries, Inc.; Dallas, Texas, which manufactures a coring drill (See Section 3.1).

AII other input values were estimated by the staff of RE/SPEC Inc. 
TABLE 4.3

DRILL SIMULATION INPUT FOR

IN-THE-HOLE PERCUSSION DRILL

1. Drill Penetration Rate

0.5

(feet per minute)

2. Drill Steel Needed

6.0

(feet drilled per addition)

3. Drill Steel Addition Rate

5.0

(minutes per addition)

4. Drill Steel Subtraction Rate

5.0 (minutes per subtraction)

5. Removal of Cuttings (minutes per foot drilled)

6. Set Up Time

(minutes at each hole)

7. Take Down Time

(minutes at each hole)

8. Tram Time Between Holes (minutes)

9. Cost of Drill Steel (per replacement)

10. Number of Holes before Drill Steel Replacement

11. Cost of Drill Bits (per replacement)

12. Number of Holes before Drill

600 Bit Replacement

13. Cost of Power 20.0

14. Power Consumption per hour

15. Machine Purchase Price

The input values numbered 13 and 15 were supplied by Ingersol1-Rand Company; Seattle, WA which manufactures an in-the-hole Percussion Drill (See section 3.5).

All other input values were estimated by the staff of RE/SPEC Inc. which includes an underground equipment design engineer previously employed by Ingerso11-Rand Company. 
TABLE 4.4

DRILL SIMULATION INPUT FOR

ROTARY DRILL WITH TRICONE BIT AND HOLE ENLARGER

1. Drill Penetration Rate

(feet per minute)

2. Drill Steel Needed

(feet drilled per addition)

3. Drill Steel Addition Rate

(minutes per addition)

4. Drill Steel Subtraction Rate

(minutes per subtraction)

5. Removal of Cuttings

(rainutes per foot drilled)

6. Set Up Time

(minutes at each hole)

7. Take Down Time

(minutes at each hole)

8. Tram Time Between Holes (minutes)

9. Cost of Drill Steel

(per replacement)

10. Number of Holes before Drill

400

Steel Replacement

11. Cost of Drill Bits

10.0

10.0

10.0

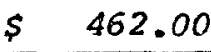

(per replacement)

12. Number of Holes before Drill

Bit Replacement

13. Cost of Power

(cent per kwh)

14. Power Consumption per hour (kw)

15. Machine Purchase Price

The input values numbered 2, 9, 10, 11, 12, and 15 were supplied by Cyclone Drill Company; Orrville, OH which manufactures a Rotary Drill (See section 3.4) and by Reed Tool Co.; Los Vegas, NV which sells Tricone Bits with a Hole Enlarger。

All other input values were estimated by the staff of RE/SPEC Inc. 
TABLE 4.5

DRILL SIMULATION INPUT FOR

ROTARY DRILL WITH DRAG BIT AND AUGER

1. Drill Penetration Rate 0.9

(feet per minute)

2. Drill Steel Needed (feet drilled per addition)

3. Drill Steel Addition Rate 5.0 (minutes per addition)

4. Drill steel Subtraction Rate 2.0 (minutes per subtraction)

5. Removal of cuttings (minutes per foot drilled)

6. Set Up Time 60.0 (minutes at each hole)

7.. Take Down Time 20.0 (minutes at each hole)

8. Tram Time Between Holes 30.0 (minutes)

9. Cost of Drill Steel (per replacement)

10. Number of Holes before Drill 500 Steel Replacement

11. Cost of Drill Bits (per replacement)

12. Number of Holes before Drill Bit Replacement

13. Cost of Power (cents per kwh)

14. Power Consumption per hour $(k w)$

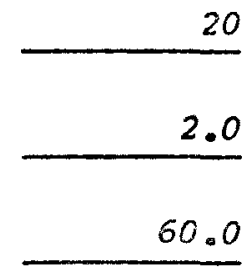

15. Machine Purchase Price

The input values numbered 2, 5, 9, 11, 14, and 15 were supplied by Acker Drill Company; Scranton, PA which manufactures a Rotary Drill (See Section 3.2). All other input values were estimated by the staff of RE/SPEC Inc. 


\section{$\underline{T A B L E} 4.6$}

Drill Simulation Results for Lower Limit of

12 inch diameter canisters, two canisters per hole

\begin{tabular}{|c|c|c|c|c|c|c|c|}
\hline DRILL SYSTEM DESCRIPTION & $\begin{array}{l}\text { NUMBER OF } \\
\text { HOLES MADE } \\
\text { AVAILABLE }\end{array}$ & $\begin{array}{l}\text { HOLE } \\
\text { DIAMETER } \\
\text { (INCHES) }\end{array}$ & $\begin{array}{l}\text { NUMBER OF } \\
\text { DRILL YEARS }\end{array}$ & $\begin{array}{l}\text { DRILL TIME } \\
\text { PER HOLE } \\
\text { (MINUTES) }\end{array}$ & $\begin{array}{c}\text { MAX. HOLES } \\
\text { PER DAY }\end{array}$ & $\begin{array}{c}\text { COST PER } \\
\text { HOLE }\end{array}$ & $\begin{array}{l}\text { TOTAL } \\
\text { COST }\end{array}$ \\
\hline $\begin{array}{l}\text { Bucket Excavator, Rotary } \\
\text { Drill Mounted on Walking } \\
\text { Beams }\end{array}$ & 50246 & 20 & 54 & 66.67 & 4.2 & $\$ 163.90$ & $\$ 8,186,693$ \\
\hline $\begin{array}{l}\text { Core Dri.l.1, } \\
\text { Skid Mounted }\end{array}$ & 50246 & 20 & 48 & 85.00 & 4.9 & $\$ 239.10$ & $\$ 12,013,819$ \\
\hline $\begin{array}{l}\text { In-the-hole Percussion } \\
\text { Drill Wi th Button Bits, } \\
\text { Crawler Mounted }\end{array}$ & 50246 & 15 & 52 & 110.00 & 4.1 & $\$ 85.41$ & $\$ 4,291,511$ \\
\hline $\begin{array}{l}\text { Top Head Drive Rotary Drill } \\
\text { With Drag Bits/Continuous } \\
\text { Auger, Rubber Tire Carrier }\end{array}$ & 50246 & 20 & 48 & 44.67 & 4.8 & $\$ 154.73$ & $\$ 7,774,564$ \\
\hline $\begin{array}{l}\text { Top Head Drive Rotary Drill } \\
\text { With Hole Enlarger, } \\
\text { Crawler Mounted }\end{array}$ & 50246 & 20 & 61 & 120.00 & 4.0 & $\$ 133.38$ & $\$ 6,684,518$ \\
\hline
\end{tabular}

Note: All costs in this table are based on drilling holes with a 25 foot depth. The number of holes made available by each dxill is slightly more than the number required because all rooms in the simulated repository were completely drilled. 
TABLE 4.7

EFFECIS OF REPOSITORY SIZE ON DRILL STMULATION RESULTS

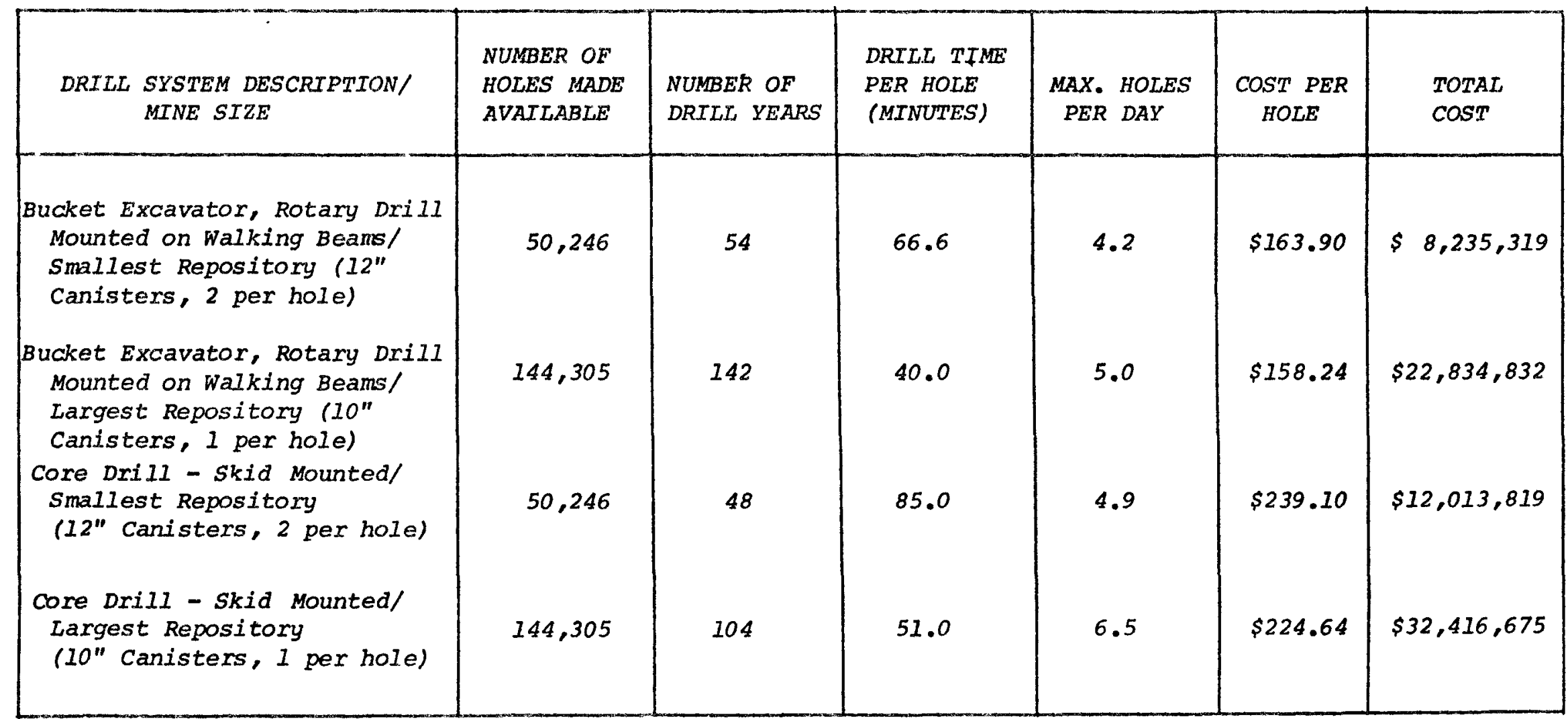

Note: All costs in this table are based on drilling 20-inch diameter holes with depths of 15 or 25 feet depending upon the number of canisters per hole. 


\section{REFERENCES}

(1) Personal Communication, involving Letter and Attachments from Dr. William C. MCClain of the Holifield National Laboratory to Dr. Paul F. Gnirk of RE/SPEC InC., dated January 17, 1975.

(2) Grams, William H.: "Design Aspects of the Alpha Repository: II. Conceptual Layouts of Underground Storage Facilities", Technical Memorandum Report RSI-0028 (June 30, 1975), pp. 12-28. 


\section{APPENDIX $A$}

Drill simulation Output Example

LARGE HILF DRTLLTHA EWIIPMENT

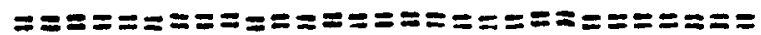

\section{IAFORNATION ANA NRTLL CYCLE SIMULATION}

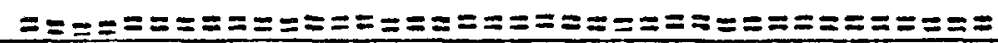

GENER II INERBNATTIN

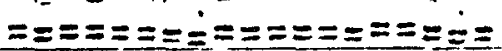

$\frac{\text { NDYIL, TYPF. }}{\text { BUCKET DHTLL }}$

PIT TYPF.

CARBIDE TIPPED HUT.KET / SCNPING KELLY

VAME, MANEL.. MODEL 1503 W/MOIIFTED SHOMT NERRICK

AANIFACTIRE / NAWE, ADUNESS, PHIME, COMTACT.

C:IL FID DTV. SHITH

SANTA FE SDZINGS, CL

PHYSITVI LOERATING CHARICTERISTTCS

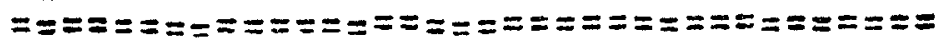

B!llK ST>E. $15 F T H, 81,7 \%$

WETGHT (IFS).. 19000

PHFR SIIRCE.

100 H.P. FLEC.

SOFAIFIR DETAILS DN DILLI UR MEIHJD.. DELOPS 15.0\% L3S. NO N PRFSSURF WITH CROUD A.VD 25,000 LBS. IF DRILL TIEO NOUN

QUTTING BFAIVAL MFTHOD CUGRFGTE1.. BUCKET CAN DUAP OTOFCILY ONTO CONVEYOAORILL HELDEQ SIIMGS RUCKET ANO NUMPS.

SPFEIAL MANDOWFR REOUITFMENTS FUR OPEPATION TR MA INTFNANCE.. NONE - REJUIKES OHIS VORMAL COVSTRUCTIAN MACHINERY MFCHANTC 
SOFCIAL VENTILATION PEUUIQEMFNTS.. DUST CONTROL

HUTSTING SPFCIFICATTONS - RRFAKUNWH OF COMPONFAITE.. DEQRICK FOLOS TO YTELIS Q IS HEIGHT OF $A$

FEET. FUTHEQ BREAKONNN POSSIALE

DPILLINIE SPFCIFICITIONS

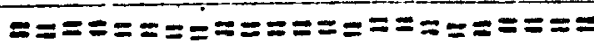

HOLF DIAMETE'
20

HOI.F DFOTH (FEET)..

25

HOL $=$ SHACING (FFET NIN CENTER) .

4

NIIMZER OF HOLES PER ROON..

518

nRIILIMR MRIFT (INCHES TN 39 FEET).

$6 . n$

DRILLI'IS RATFC

$==\approx===\equiv======$

DRTIL PENETHATTON RATES (FEFT PER MIN!ITE)...

NOIIL STEEL NEENED (FEET DFTLLEU PER AONTTION).. 30.0

WRIL STEEL ADOITIOA RATE (MINUUIES PEP ANOITION).

DETIL CTFEL SUATRACTIUM RATE (MINIITES PEQ REANUAI)..

0.0

RFAMVAI OF CUTTIVSS IN ADUITION TU TJIF QEQUIOER

FOA PEHETRATION (MINUTES PEA FOTT OR]LLFOI..

1. 11

MAT TEMANCE TIMF (MINUTES RFOUIIHED PER HOUR OF NOILL. DPERATIONT..

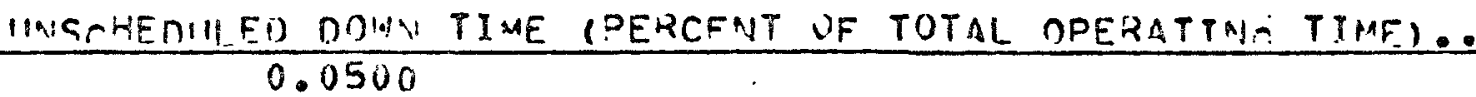


(RSI-0032)

SFT_IJP TTME (MINUTES TO SET IIP ISRILL AT EACH HAI_R) $\ldots \quad A=3$

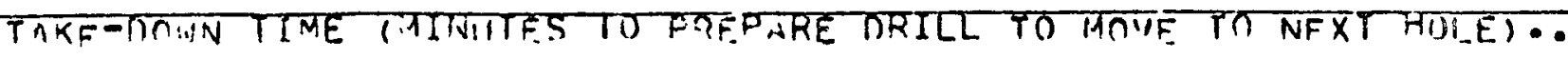
20. 0

TRAM TIAF. HETWEFN HOLES (MTNIITFS) -.

$30: 0$

20RINUCTRON HOUPG (HOURS AT ORTLL SITE PFR SHTFT)..

COSTS - DE $2 S D N$ NEL

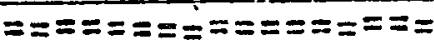

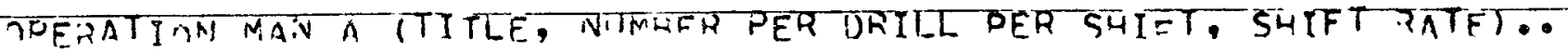
DPERAT'SH

7isen

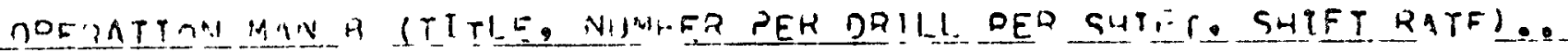
JPFRATUR HELPFR

55.07

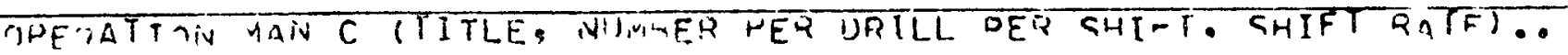

$$
1.00
$$

HAT TEVAVE HAN (NU.AQEA PEK NRILL PER DAY, SHTET PATF)..

61). 0

COSTS - IATFOTML

$\equiv=\equiv \equiv \equiv==\div=\equiv=\equiv===$

CIST OF NPILL STEEL INOLLAKS PFW REPLACEAENTI... 50011.00

. Ji) WRER nF HULES BEF RHE तRILL STEEL REP_ACFMENT . . 500

ENST OF DQILL RITS IONLLAKS DER

RFOLOCENENTI..

$20{ }^{\circ} .00$

WIIAEA OF HOLES BEFARF DRILI BIT REPLACEMENT) 
COST OF DONER (CENTS DER KH)...

$$
\text { ?. } 0 n
$$

PNHER CONSU IPTION PFR HOUR OF OPERATION (KW).

COST OF MAINTEIVANCE MATERIAL PEH HOUR OF OPERATINN.6.0O

COSTC_CAOTTIL

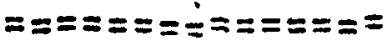

MACHINE PIIACHASE PRTCE..

88970.00

MACHINE LIFE EXPECTFD..

SILYAGE VALIE (OERCFNT OF PIRCHASE PRICE)

0,1000

COST OF CAPITAL (INTEZEST OQ INUESTMENT RATE). $0.0 A C O$

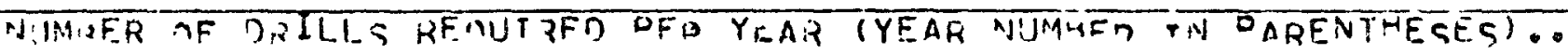

\begin{tabular}{|c|c|c|c|c|c|c|c|c|c|}
\hline 11 & 0 & 131 & 1 & $(3)$ & 1 & 41 & 1 & 5) & 1 \\
\hline 16 & 1 & $(7)$ & 1 & $(8)$ & 1 & $9 i$ & 1 & $(10)$ & 1 \\
\hline 111 & 3 & $(12)$ & 7 & $(1.3)$ & 3 & $(14)$ & 3 & $(15)$ & 3 \\
\hline$1 \longdiv { 6 }$ & 3 & $(17)$ & 3 & (1म) & 3 & 1109 & 3 & $(20)$ & 3 \\
\hline 121 & 3 & (2?) & 3 & $(23)$ & 3 & $(\geq 4)$ & 3 & $(25)$ & 3 \\
\hline
\end{tabular}

DRILL "ANBILTTY

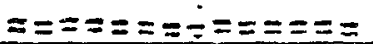

METHOD TF TOANSODHT..

MIUNTFD ON NALKTIVA BEAMS

$\frac{3 \text { P.n) THAM TIME (DAYS)... }}{5.00}$

PANFL TISAY TIME (DAYS)..

10.00

NIIMOER AF DRILLS ALIOVEN IPI A RUO:A... 
CANISIED $12 P I$ IAL

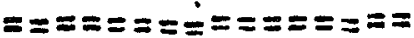

CAHTSTE'S SER YFAR (YEAR NUMRER IN PAFENTHESFCI..

\begin{tabular}{|c|c|c|c|c|c|c|c|c|c|}
\hline 11 & 1545 & 2) & 575 & 3) & 573 & 41 & 684 & 5) & 859 \\
\hline (b) & 11106 & 71 & 12.99 & B) & 1512 & 4) & .767 & (10) & 2070 \\
\hline (1)11) & 2340 & (1)?) & 2,343 & (1)31 & $? 993$ & $(1 / 4)$ & 9315 & $(15)$ & 7799 \\
\hline$(16)$ & 4207 & $(17)$ & 4792 & $(13)$ & $538 \%$ & $(19)$ & $: 1119$ & $120)$ & 6647 \\
\hline$(21)$ & 7437 & (22) & $8>48$ & (23) & $914 !)$ & $(\geq 4)$ & $=127$ & $(25)$ & 11130 \\
\hline
\end{tabular}

NIIMAER OF CANISTEYS PER EAPLACEMENT HOLE. 2

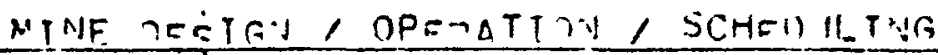

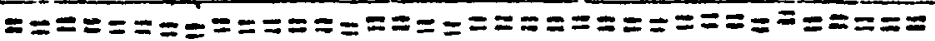

NAMU $=$ OF MI NFE.

S.M IFI AKE - LOWEW!I IIT

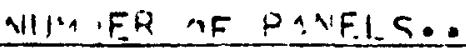

5

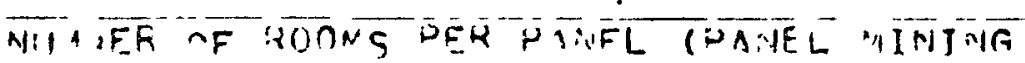

SEO IENCE IN PADEVTHFSESI..

$\begin{array}{lrrrrrrrrrr}(1) & 19 & (2) & 10 & (3) & 19 & (4) & 20 & (5) & 20 \\ (6) & -0 & (2) & -0 & (2) & -0 & (29 & -0 & (10) & -0\end{array}$

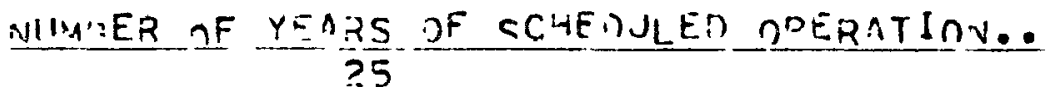

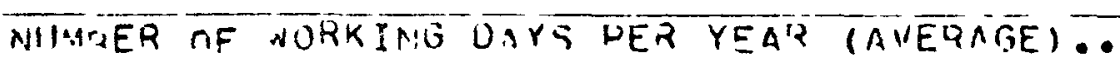
$25 n$

NIIMIER AE SHIFTS IED DAY..

RONA.4 AVAILAHTLITY..

DATA IS SIIPPLIED RY WININIG SIMUILTIOH - WOGQMM 
Foliow

LI IO PROCFSS IASEI) DN THE AGUVE DATA.

DRILLIHAR RATES

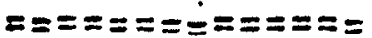

BASFD NA ROOM AVAILABILITY, DQILLING WTLL START. DAY 58 YEAR 2

NOT1L TTMF PER HOLF (WIPIJTFS)..

$$
66.67
$$

MAXTMUM NIMAER OF HILLS PER MAY..

$$
\text { 4.2.1 }
$$

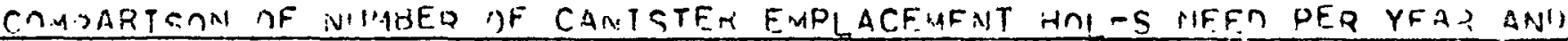

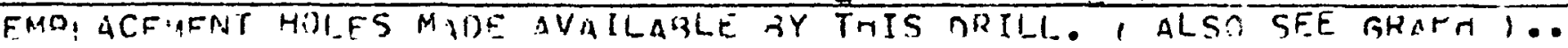

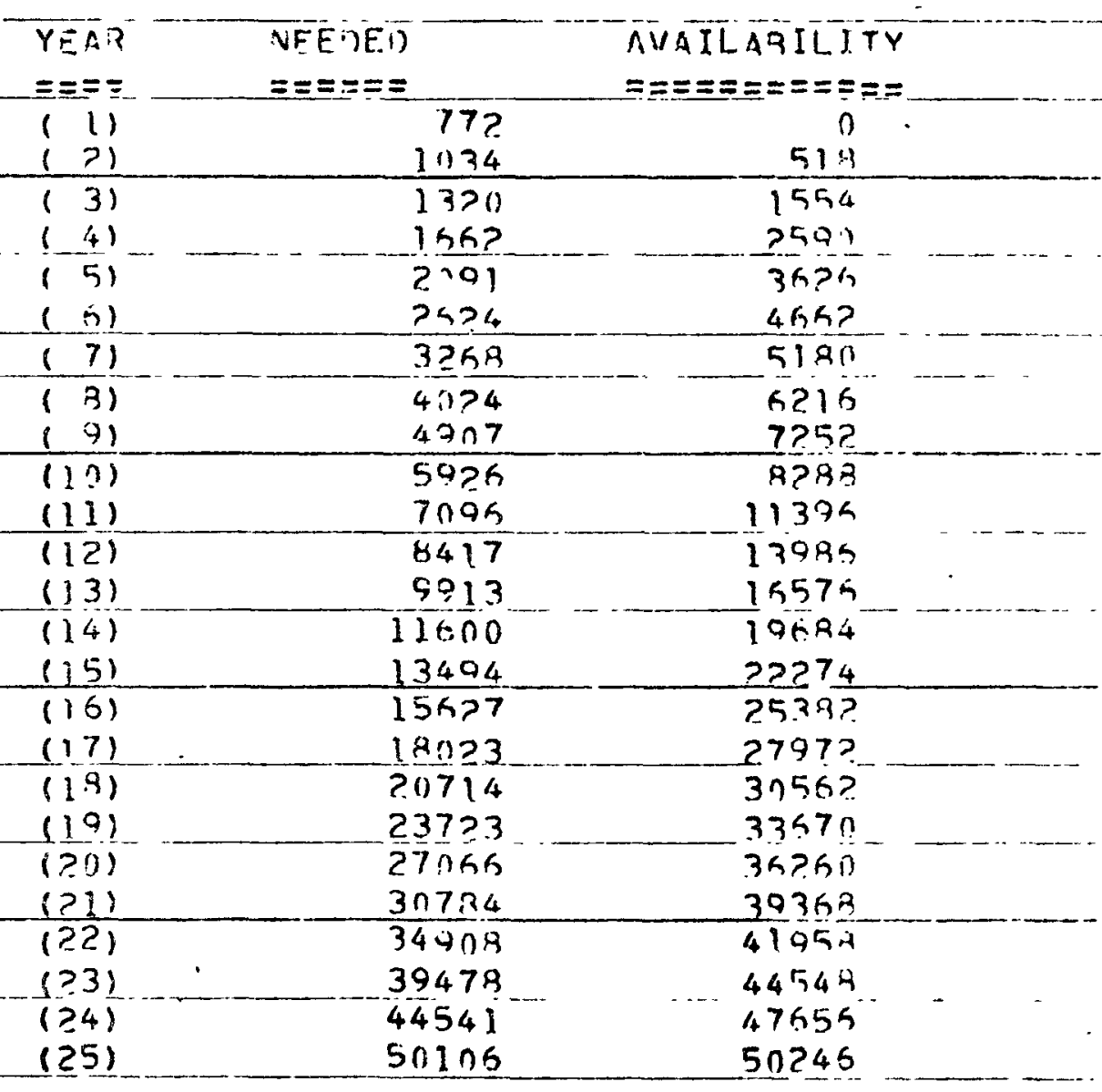




\begin{tabular}{|c|c|c|}
\hline YEAR & & IDLE UKILL UAYS \\
\hline$==\equiv=$ & & 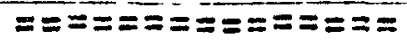 \\
\hline $1 \quad 1$ & 1 & 0 \\
\hline 12 & ) & 0 \\
\hline 1 & 1 & 0 \\
\hline 1 & ) & 0 \\
\hline 1 & 1 & $n$ \\
\hline 1 & ) & 0 \\
\hline 1 & 1 & 9 \\
\hline 1 & ) & 0 \\
\hline 19 & 1 & 2 \\
\hline 110 & 1 & 0 \\
\hline 111 & 1 & $n$ \\
\hline 112 & 1 & 0 \\
\hline 113 & 1 & 0 \\
\hline 114 & ) & $n$ \\
\hline 115 & $i$ & $n$ \\
\hline 116 & 1 & 0 \\
\hline 117 & 1 & 0 \\
\hline 118 & 1 & $n$ \\
\hline 119 & 1 & 0 \\
\hline 120 & 1 & 0 \\
\hline 121 & 1 & $n$ \\
\hline 122 & 1 & ? \\
\hline 12.3 & 1 & 0 \\
\hline 124 & 1 & 0 \\
\hline 125 & 1 & 67 \\
\hline
\end{tabular}


DQILLTIIn CnCTE

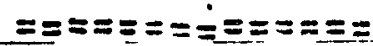

TOTA1. CISTS PEP YEAT (ALSO SFE GRAPH)..

\begin{tabular}{|c|c|c|}
\hline YFAR & & COST \\
\hline $\begin{array}{l}=== \\
1 \quad 1\end{array}$ & 1 & 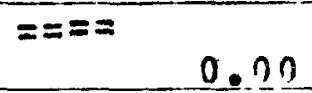 \\
\hline $\begin{array}{l}2 \\
1 \\
1\end{array}$ & 1 & $\begin{array}{l}132466.03 \\
148290.47\end{array}$ \\
\hline $\begin{array}{ll}14 \\
1 & 5\end{array}$ & ? & $\begin{array}{l}148200.47 \\
148290.47\end{array}$ \\
\hline $\begin{array}{l}6 \\
1 \quad 7 \\
\end{array}$ & $\frac{1}{1}$ & $\begin{array}{r}148290.47 \\
149389.49\end{array}$ \\
\hline $\begin{array}{l}1 \\
1 \\
1\end{array}$ & 1 & $\begin{array}{l}148290.47 \\
149290.47\end{array}$ \\
\hline 110 & ) & 148290.47 \\
\hline$\left(-\frac{11}{12}\right.$ & $\frac{1}{1}$ & $\frac{459593.41}{40226.2 .97}$ \\
\hline 113 & i & 402263.97 \\
\hline $\begin{array}{ll}14 \\
1 & 15\end{array}$ & i & $\begin{array}{l}454024.3 n \\
472742.47\end{array}$ \\
\hline 116 & 1 & $4295 \sqrt{3.41}$ \\
\hline 1.17 & 1 & $432 ? 42.47$ \\
\hline 18 & ) & 456.703 .595 \\
\hline 119 & 1 & $4,955^{43} .41$ \\
\hline 120 & 1 & 402262.47 \\
\hline $1 \geq 1$ & 1 & 459503.41 \\
\hline 122 & 1 & 456713.46 \\
\hline $1 \geq 3$ & 1 & $4-225 ? .07$ \\
\hline $\begin{array}{l}124 \\
1 \quad 25\end{array}$ & 1 & $\begin{array}{l}4395 \times 3.41 \\
4 \geq 7878.52\end{array}$ \\
\hline
\end{tabular}

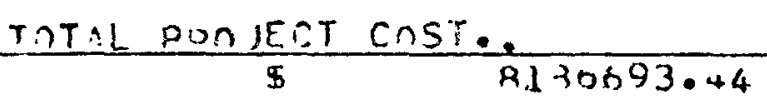

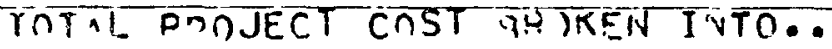

OPERATIOSC CIST:- क IAHOH CUST.. क .AATEOI H. COST..?

NAINTF VAIUEE COST.. क I. ABOA COST MATE-RIAL COST... D

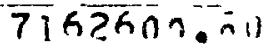
$3375 n n n$, in $37875 n n \cdot \pi 11$

$5530 n n$ 2?500n $n$ n $333 n n n$. 0

\section{CAPITAL COST..}

b

$466097 \cdot \pi 4$

AVERAGE COST PER HOLE OVER PQOJECT.$\$ \quad 163.90$ 
Comparison of Emplacement Holes Required and Emplacement Holes Produced by the Calweld Model 150B Bucket Drill

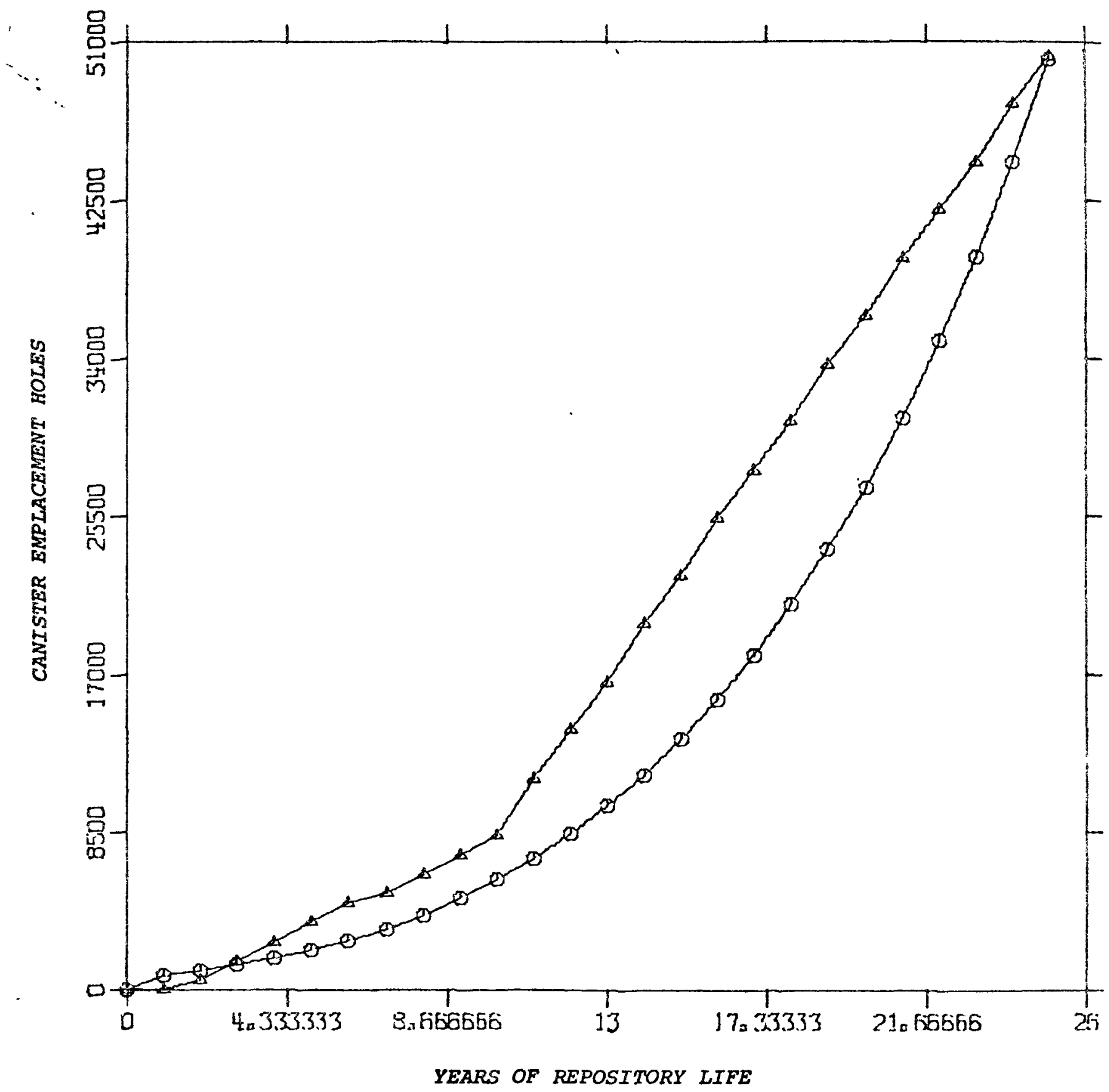

O - Emplacement Holes Required

$\Delta$ - Emplacement Holes Produced 
Percent of Drill opexation Time Per Year for Calweld Model 150B Bucket Drill

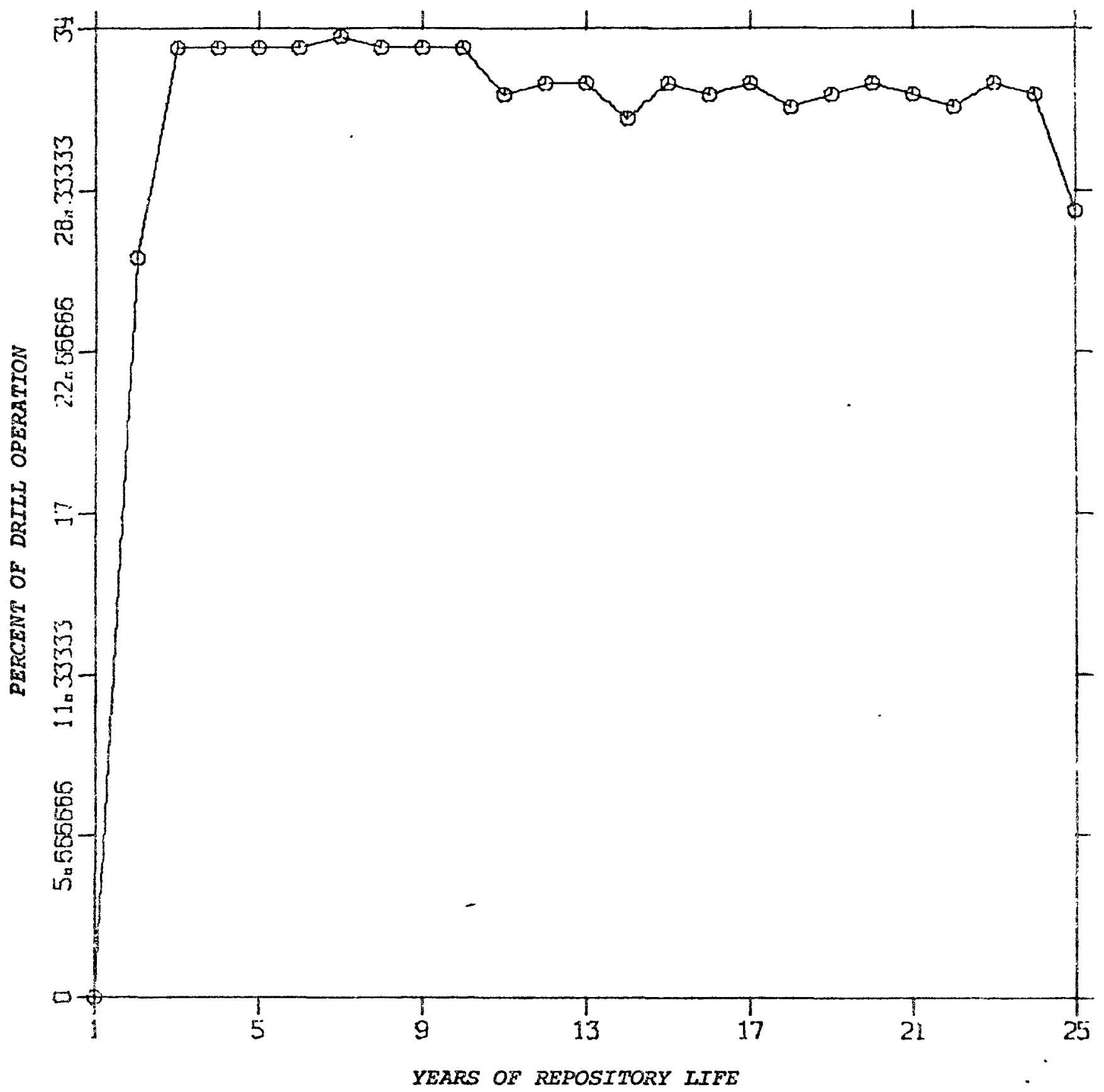


Idle Drill Days per Year Resulting From Unavailable Rooms for Drilling for Calweld Model 15OB Bucket Drill

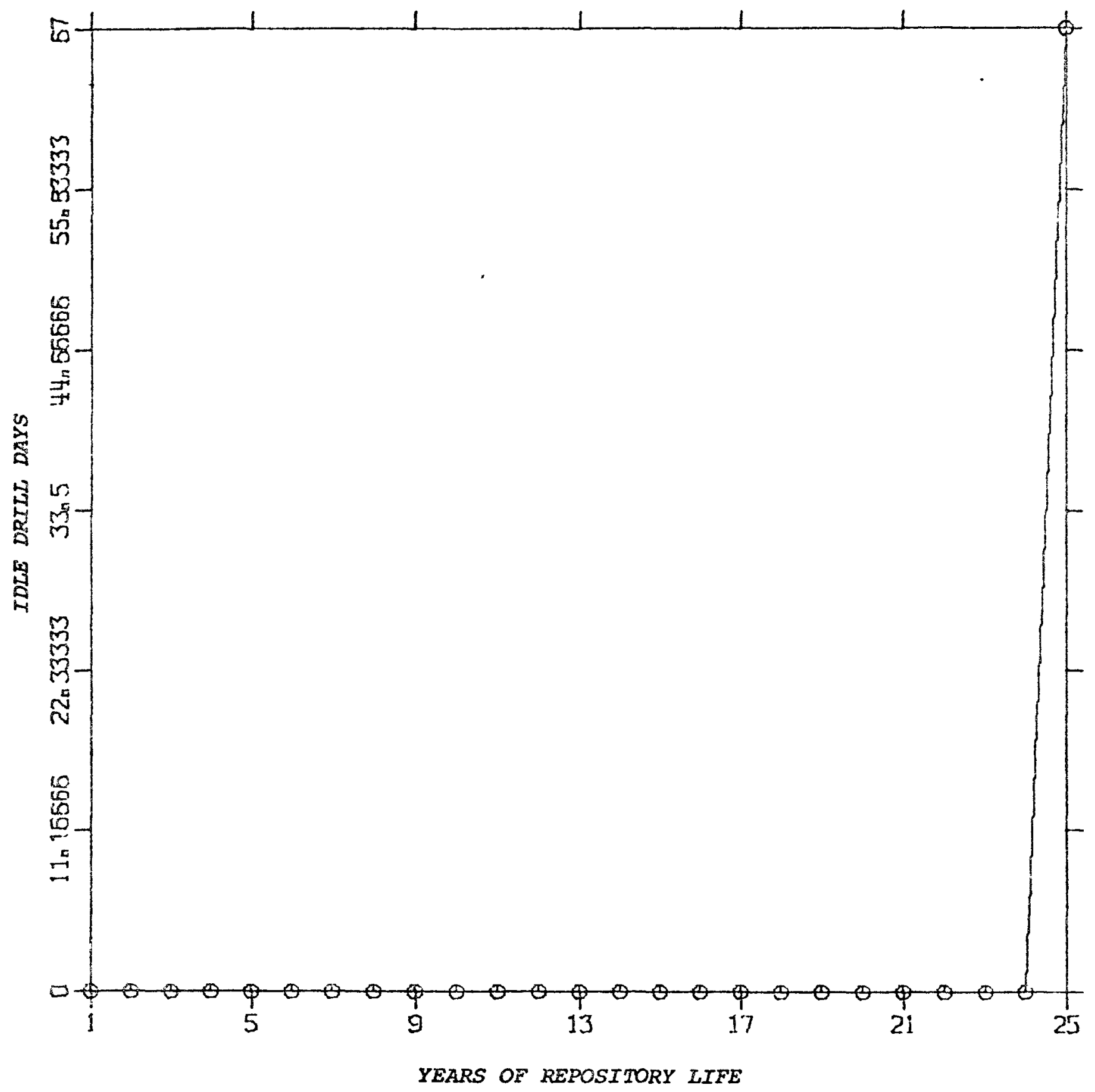




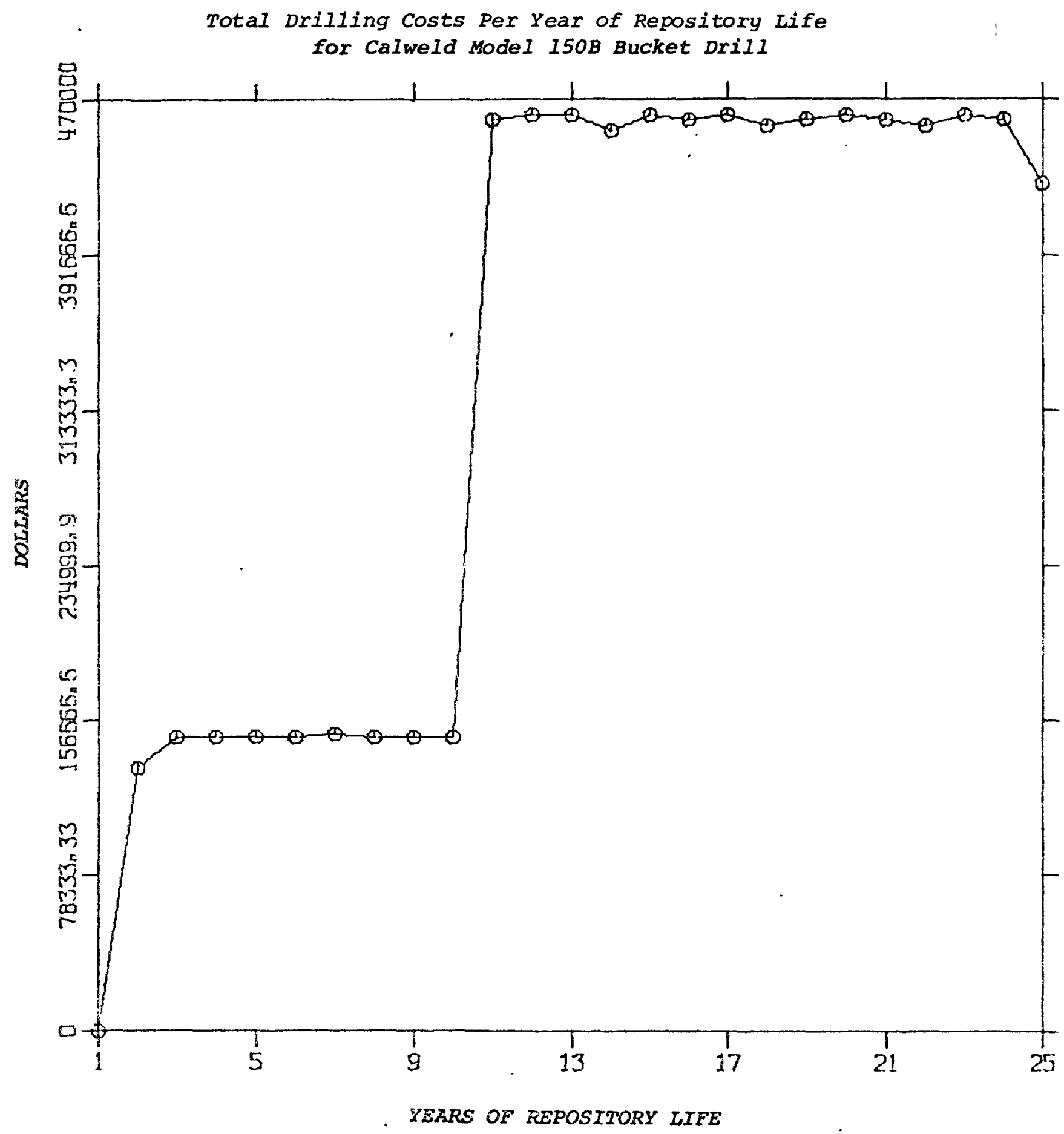

